\title{
Male and female labour force participation: the role of dynamic adjustments to changes in labour demand, government policies and autonomous trends
}

Citation for published version (APA):

Vendrik, M. C. M., \& Cörvers, F. (2009). Male and female labour force participation: the role of dynamic adjustments to changes in labour demand, government policies and autonomous trends. METEOR, Maastricht University School of Business and Economics. METEOR Research Memorandum No. 036 https://doi.org/10.26481/umamet.2009036

Document status and date:

Published: 01/01/2009

DOI:

10.26481/umamet.2009036

Document Version:

Publisher's PDF, also known as Version of record

Please check the document version of this publication:

- A submitted manuscript is the version of the article upon submission and before peer-review. There can be important differences between the submitted version and the official published version of record.

People interested in the research are advised to contact the author for the final version of the publication, or visit the DOI to the publisher's website.

- The final author version and the galley proof are versions of the publication after peer review.

- The final published version features the final layout of the paper including the volume, issue and page numbers.

Link to publication

\footnotetext{
General rights rights.

- You may freely distribute the URL identifying the publication in the public portal. please follow below link for the End User Agreement:

www.umlib.nl/taverne-license

Take down policy

If you believe that this document breaches copyright please contact us at:

repository@maastrichtuniversity.nl

providing details and we will investigate your claim.
}

Copyright and moral rights for the publications made accessible in the public portal are retained by the authors and/or other copyright owners and it is a condition of accessing publications that users recognise and abide by the legal requirements associated with these

- Users may download and print one copy of any publication from the public portal for the purpose of private study or research.

- You may not further distribute the material or use it for any profit-making activity or commercial gain

If the publication is distributed under the terms of Article 25fa of the Dutch Copyright Act, indicated by the "Taverne" license above, 
Maarten Vendrik, Frank Cörvers

Male and female labour force participation: the role of dynamic adjustments to changes in labour demand, government policies and autonomous trends

$\mathrm{RM} / 09 / 036$

\section{METEOR}




\title{
Male and female labour force participation: the role of dynamic adjustments to changes in labour demand, government policies and autonomous trends
}

\author{
Maarten Vendrik* and Frank Cörvers**
}

\begin{abstract}
This study investigates the extent and speed of dynamic adjustment of labour supply to changes in labour demand, government policies and autonomous trends. We estimate error-correction models (ECMs) for male and female participation rates in the Netherlands between 1969 and 2004. The results show significant short and long-run effects of labour demand as well as a negative autonomous trend for male participation. In contrast, we find no significant long-run labour-demand effects and a very strong positive autonomous trend for female participation. Including female and male participation as additional explanatory variables in the male and female ECMs, respectively, reveals significant substitution effects between female and male participation. For male participation the substitution effects from female participation account for the negative trend in the basic ECM, while for female participation the substitution effects from male participation counterbalance labour demand effects that are now significant. In addition, we find very significant breakpoints in male and female participation at 1994, which indicate the effects of exogenous participation-promoting policies by the Dutch governments after 1994. The adjustments of the participation rates to changes in labour demand, government policies and autonomous trends are moderately fast.
\end{abstract}

Theme: Labour supply

Key words: Labour force participation, discouraged worker effect, business cycle effects, persistence, substitution effect, error-correction model

JEL-Code: J21, J20, E32

\footnotetext{
* Corresponding author. E-mail: m.vendrik@maastrichtuniversity.nl. Department of Economics, Faculty of Economics and Business Administration, Maastricht University, P.O. Box 616, 6200 MD Maastricht, The Netherlands, tel. +31 433883638, and IZA, Bonn.

** Research Centre for Education and the Labour Market (ROA), Faculty of Economics and Business Administration, Maastricht University.
} 


\section{Introduction}

In Western-European countries the aging of the population may lead to severe problems in the decades to come. On the one hand, aggregate labour supply will stagnate and subsequently decline. On the other hand, the number of people above 65 years old will strongly rise. This will greatly raise the demand for care, and hence push up labour demand. To alleviate the resulting mismatch between labour supply and demand, governments have started to stimulate labour supply by making disability schemes less generous, discouraging early retirement, and further encouraging labour force participation of women by providing better and cheaper child-care facilities.

A major question in this respect is to which extent and how fast the labour market will adapt to these profound changes. More specifically, to which extent and in which ways will labour supply adjust to changes in labour demand? Such equilibrating effects have been observed in the ways in which the business cycle affects labour force participation rates (see e.g., Darby et al., 2001). In times of recession, rising unemployment rates and falling wages discourage individuals to search for a job (see for the Netherlands Van Mourik and Siegers, 2001). On the other hand, when the economy is booming, declining unemployment and rising wages encourage them to enter the labour market. However, these adjustments of labour supply to changes in labour demand are not instantaneous, but delayed as a result of persistence of labour supply (Clark and Summers, 1982). For example, those out of the labour force may suffer from lack of work experience and skill obsolescence, and both men and women are influenced in their labour supply behaviour by their social reference group (Kapteyn and Woittiez, 1998; Neumark and Postlewaite, 1998).

This paper incorporates these labour demand and persistence effects into dynamic errorcorrection models (ECM) of male and female labour force participation. Our models involve six basic impacts. First, when labour demand, as measured by the sum of total employment and vacancies, rises, unemployment will decrease and real wages will increase. This will encourage men and women to participate in the labour market. When labour demand falls the opposite effect occurs, which is known as the discouraged worker effect. At the institutional level, rising unemployment rates may lead to easier access to, and hence higher inflow into, disablement benefits and early retirement. Furthermore, rising labour demand will raise employment, and hence, via reinforcing work experience effects and social interactions (see Vendrik, 1998; Maurin and Moschion, 2006; Fernández, 2007), stimulate more women and men to enter the labour market or to quit later. Paradoxically, work experience effects and social interactions also lead to persistence of labour supply (see above) when a low (high) participation rate keeps employment, and hence the participation rate in the next year, on a low (high) level. Together with other persistence and counteracting effects, these inertial forces constitute the second basic impact.

Thirdly, there may be autonomous trends in aggregate labour force participation as a result of cohort and period effects. For example, younger cohorts of women tend to have more liberal social norms with respect to paid employment and to face more favourable child care facilities. Fourthly, male (female) labour demand is not only determined by total labour demand, but also negatively by 
female (male) labour supply since male and female labour supply are (imperfect) substitutes of each other. ${ }^{1}$ Such substitution between male and female labour supply will not only take place at the demand side of the labour market, but also at the supply side within families, as expressed in the added-worker effect (Prieto-Rodriguez and Rodriguez-Gutierrez, 2000; Stephens, 2002). ${ }^{2}$ Hence, in extended ECM variants we include and estimate the possible negative substitution effects of male and female labour supply on each other. Fifthly, we allow for structural breaks in the development of male and female participation due to exogenous changes in government policies with respect to labour force participation. Finally, for the last eleven years of our sample, we also assess the effects of changes in the composition of the population with respect to background characteristics like age and educational level.

To estimate our models we use time series for the Netherlands between 1969 and 2004. Stationarity, cointegration and exogeneity tests indicate that we can use single-equation ECMs for our estimations. In basic ECMs without substitution effects between male and female labour supply, we find significant short and long-run effects of labour demand as well as a negative autonomous trend for male participation. In contrast, we find only significant short-run effects of labour demand and a very strong positive autonomous trend for female participation. However, when we include female and male participation as additional explanatory variables in the male and female ECMs, respectively, we obtain significant substitution effects of female and male participation on each other. For male participation the substitution effects from female participation account for the negative trend in the basic ECM, while for female participation the substitution effects from male participation counterbalance labour demand effects that are now significant in the long run as well. In addition, we find very significant breakpoints in male and female participation at 1994. From 1993 to 1994 the long-run levels of male and female participation rates exhibit a large upward jump, to which the actual participation rates gradually adjusted in the ensuing years. We interpret these adjustments as the result of exogenous participation-promoting policies by the Dutch governments in that period.

The equations with breakpoint indicate only a partial long run response of the participation rates to changes in labour demand for men (for about a half) and, as explained above, a zero net longrun response for women. The adjustments over time of the participation rates to their long-run equilibria are moderately fast, i.e. about 50 percent per year. We also tested for asymmetries in the impact of labour demand on participation due to individual habit and human capital formation (also by means of a new specification), but we did not find significant effects.

This study contributes to the literature by offering a comprehensive estimation of the extent and speed of dynamic adjustments of male and female labour force participation to changes in labour demand, government policies and autonomous trends, and by highlighting the interaction between male and female participation by way of mutual substitution. Especially the latter interaction seems to

\footnotetext{
${ }^{1}$ Such (perfect or imperfect) substitution between male and female labour supply also plays a role in models of occupational segregation and wage discrimination (Bergmann, 1974; Borghans and Groot, 1999).

2 This is not an effect of substitution in production or consumption, but we interpret it as a kind of substitution effect in a broad sense.
} 
represent a novelty of our approach.

The paper is structured as follows. Section 2 discusses the employed time series of male and female participation rates and our measure of labour demand, and analyses the six basic impacts that underly the ECM models. Section 3 presents the model selection and estimation results for the basic ECMs for male and female participation. In Section 4 the analysis is extended by introducing the interaction between male and female participation rates. Then, for the last ten years of the sample, Section 5 presents a decomposition analysis of the relative contributions of all the variables to the upturn and downturn in that period. Section 6 concludes.

\section{Dynamics of Dutch labour force participation}

The three main time series of our interest are those of male participation rate $P_{m}$, female participation $P_{f}$, and labour demand rate $D$. They are shown in Figure 1. The participation rates concern the men and women between 20 and 64 years old who are employed for at least twelve hours per week, or are unemployed and searching for a job of at least twelve hours per week. ${ }^{3}$ Labour demand rate $D$ is defined by total labour demand as a percentage of the potential labour force, which comprises all persons between 15 and 64 years old. Total labour demand equals the sum of the number of persons employed for at least twelve hours a week and the number of vacancies. ${ }^{4}$ The time series for participation rates, employment and vacancies have been constructed by the Netherlands Bureau of Economic Policy Analysis and Statistics Netherlands (CPB, 2005, Annex 7) on the basis of labour force and vacancy surveys held by Statistics Netherlands. We have chosen labour demand rate $D$ as an indicator of labour demand rather than the general wage level $w$, unemployment rate $u$ (Clark and Summers, 1982), or (business sector) GDP $Y$ (Darby et al., 2001) since $D$ is a more comprehensive indicator of labour demand effects than $w$ or $u$, since $D$ is less endogenous with respect to participation rates $P_{m}$ and $P_{f}$ than $u$, and since $D$ is a more direct indicator of labour demand than $Y$ and may even be less endogenous than $Y$ (note that $Y$ depends on employment as well as wages; see below). Moreover, labour demand rate $D$ has the advantage of providing a benchmark of complete adjustment of male and female labour force participation to labour demand where a 1 percent point rise/fall in the labour demand rate leads to 1 percent point rises/falls in the male and female participation rates (see Section 3.2 for more details).

\section{Insert Figure 1}

\footnotetext{
${ }^{3}$ In the Netherlands all statistics on employment and unemployment use the twelve-hours limit instead of the internationally used one-hour limit. This implies that persons looking for part-time jobs of less than twelve hours are not considered as labour supply.

${ }^{4}$ The number of employed persons concerns everybody between 15 and 64 years old. The number of vacancies excludes the government and education sectors. Before 1994 also the number of vacancies in sheltered workshops and at employment agencies was excluded. We do not expect this to have any impact on our analysis since these numbers were low before 1994.
} 
As shown by Figure 1, the Netherlands has undergone a huge increase in female labour force participation, from 34 percent point in 1969 to 63 percent point in 2004. This development is similar to the increase in female participation in many other countries of the European Union and the U.S. In contrast, male labour force participation in the Netherlands, as in many other countries, declined until the beginning of the 1990s. ${ }^{5}$ In 1969 male participation was 94 percent point and dropped to 80 percent point in the first half of the 1990s. After this dip male participation increased to the same level at the beginning of the new millennium as at the beginning of the 1980 s, i.e. about 85 percent point. Finally, Figure 1 shows that the labour demand rate decreased to a minimum level in 1984, and then gradually increased to the highest level during the period under consideration in 2001.

In this paper we are especially interested in the dynamic effects of changes in labour demand rate $D$, government policies and autonomous trends on male and female participation. Below we will discuss the various effects on the developments of male and female labour force participation rates $P_{m}$ and $P_{f}$ between 1969 and 2004. Therefore, we will now subsequently discuss (i) several channels by which changes in labour demand rate $D$ affect male and female participation, (ii) persistence and other feedback effects on participation, (iii) possible sources of autonomous trends in participation rates, (iv) substitution and added-worker effects between male and female participation, (v) possible effects of changes in government policies on participation, and (vi) effects of changes in compositional variables.

(i) A fall (rise) in labour demand rate $D$ will lead to a fall (rise) in employment ratio $E_{i}, i=$ $m, f$, defined as male/female employment in persons as a percentage of the potential labour force of men/women. In its turn, this will raise (lower) the unemployment rate $u_{i}$, which is the number of unemployed men/women as a percentage of the labour force. At the same time, the fall (rise) in labour demand rate $D$ will lower (raise) the vacancy rate $v$, which is here defined as the number of vacancies as a percentage of total labour demand. These changes in $u_{i}$ and $v$ have three effects that are more or less related to the discouraged/encouraged worker effect.

(ia) Rising unemployment and falling vacancy rates will discourage unemployed persons to search for a job inducing them to exit the labour force (fall in $P_{i}$ ). Conversely, declining unemployment rates and rising vacancy rate will encourage non-participating persons to enter the labour force (rise in $P_{i}$ ). In an empirical analysis for four countries Darby et al. (2001) found significant responses of participation rates to downward and upward fluctuations in the business cycle. ${ }^{6}$ In the context of our analysis for the Netherlands, the business cycle fluctuations work via the labour demand rate. Figure 1 shows that the Netherlands faced sizable drops in labour demand during the recessionary years at the beginning of each decade after 1969.

\footnotetext{
${ }^{5}$ See European Commission (2001), Darby et al. (2001) and Juhn (1992) for analyses of the changes in labour force participation in European countries, Japan and the U.S.

${ }^{6}$ They also found that the fall in participation rates of older women during cyclical downturns was significantly larger than the rise in participations rates in upturns (see Section 4.3 for more on this). The countries included in the empirical analysis were France, Japan, the United States and Sweden. The 'discouraged worker effect' turned out to be most prevalent in the former three countries.
} 
(ib) In the longer run, rising unemployment rates and falling vacancy rates will suppress wages $w_{i}$ prevailing for men and women, and hence participation rates $P_{i}$. Conversely falling unemployment rates and rising vacancy rates will push $w_{i}$, and hence $P_{i}$ upwards. This may be referred to as wage effects. Nevertheless, these wage effects may also be considered as part of the discouraged/encouraged worker effect, since the expected wage benefits from job search decrease when the labour market becomes looser due to both a lower probability of finding a job and a lower wage.

(ic) At the institutional level, rising unemployment and falling vacancy rates in the Netherlands from 1969 to the beginning of the 1990s seem to have led to easier access to, and hence higher inflow into, disablement benefits and early retirement. This may explain the falling male participation rates till the beginning of the 1990s. As argued by Hassink et al. (1997), until then it was rather common that older workers could easily stop working without a significant income loss when firms had to shrink their businesses due to the shortfall of demand. Because of lower separation costs it was also attractive for firms to make employees eligible for disability benefits instead of dismissing them. $^{7}$ Apart from that, it has been shown by Kapteyn and Vos (1997) and Börsch-Supan (1998) that the incentives for early retirement at the age of 60 were very strong in the Netherlands. Conversely, falling unemployment rates and rising vacancy rates during the last fifteen to twenty years seem to have contributed to government reforms of disablement-insurance and pension systems and ensuing later retirement and outflow out of disablement. Rules for the eligibility for disability benefits have become more stringent, the various pension plans have made it less profitable for employees to exit the labour force at an early age (Euwals et al., 2004), and subsidies for the enrollment in higher education have been lowered (OCW, 2001). Also the various tax reforms in the Netherlands to induce women to participate in paid employment (Vlasblom, 1997; CPB, 2001) may be interpreted in a similar way. These institutional and policy effects of labour demand are here considered as dis/encouraged worker effects in a broad sense.

(id) In addition to these three effects, a rise in the employment ratio $E_{i}$ due to a rise in $D$ will, as a result of social influencing and interactions between employed and non-employed individuals, directly raise labour force participation rates $P_{i}$. This is referred to as bandwagon effects. ${ }^{8}$ In the longer run, such bandwagon effects may work via adaptation of social norms to higher levels of employment. This may especially hold for married women, older employees, and low-skilled employed (see e.g. Vendrik, 2003a). Bandwagon effects may also work between institutions and in a political context when, for instance, a change in policy of one government institution or political organization to raise labour force participation induces others to change their policy as well. In the longer run, a rise in the employment ratio $E_{i}$ due to a rise in $D$ will also enhance the work experience of employed persons,

\footnotetext{
${ }^{7}$ See for more recent developments in the Netherlands Koning and Van Vuuren $(2007,2009)$. For the United States Juhn (1992) and Autor and Duggan (2003) show adverse effects of higher disability benefit levels on participation rates.

${ }^{8}$ See Leibenstein (1950) for the case of consumption. See Clark and Summers (1982), Kapteyn and Woittiez (1998), Neumark and Postlewaite (1998), Vendrik (1998, 2003b), and Maurin and Moschion (2006) for the case of labour supply.
} 
and hence raise their human capital and wages (Eckstein and Wolpin, 1989) and increase their habituation and attachment to paid work (Clark and Summers, 1982). This will make them more reluctant to leave the labour market when they (especially women) get children or when they get older. This will then raise labour force participation rates $P_{i}$ in a longer run.

(ie) Besides all these effects from labour demand to participation, there will also occur reverse feedback effects from participation to labour demand. For example, there is a feedback from a higher (lower) participation rate $P_{i}$ to a higher (lower) unemployment rate $u_{i}$ as $u_{i}=1-\left(E_{i} / P_{i}\right){ }^{9}$ This will lead to lower (higher) wages $w_{i}$, which improves (worsens) the competitive position of the export sector of the economy, and hence boosts (curbs) labour demand $D$. Another feedback effect occurs if at a lower $P_{i}$, and hence lower employment ratio $E_{i}$ (see footnote 9), the vacancy rate $v=1-(E / D)$ rises ( $E$ is the overall employment ratio of men and women together). This will induce employers to lower the number of outstanding vacancies, and will also push up wages $w_{i}$, both leading to a lower labour demand rate $D$. However, the feedback effects from unemployment and vacancy rates to wages and outstanding vacancies seem to be delayed in a labour market like the Dutch, and we find indeed econometric evidence in our estimations (see Sections 3.2 and 3.3) that the delays take at least one year. This makes labour demand rate $D$ at most lagged endogenous, and hence predetermined relative to participation rates $P_{i}$.

(ii) Another important determinant of participation is the participation rate lagged $P_{i t-l}$. The dependence tends to be positive and describes persistence of the participation rate. Labour supply is expected to be strongly dependent on past behaviour. In particular, Clark and Summers (1982) argue in favour of the persistence hypothesis. Those who are employed will not easily stop working, because of habituation, obligations towards the employer, and financial and family commitments. Those out of the labour force may suffer from lack of work experience and skill obsolescence (Van Loo et al., 2001), ${ }^{10}$ or may have built up household-specific capital and be involved in raising their children. Moreover, both men and women may recoil from the cost of behaving differently from their 'reference group'. For example, if the norm of the reference group of a wife is not working and raising the children, she usually will incur high psychological costs when accepting a job (Akerlof, 1980; Vendrik, 1993). These work experience, adjustment costs and bandwagon effects at the individual, household and group level hinder individuals to change their labour market behaviour. These persistence effects are modelled by a positive dependence of the participation rate on the participation rate lagged $P_{i t-1}$, which accounts for a higher (lower) level of $P_{i t-1}$ leading to a higher (lower) employment ratio $E_{i t(-1)}$, and hence via (lagged) work experience and bandwagon effects to a higher (lower) level of $P_{i t}$. However, this dependence also accounts for a direct dependence of the

\footnotetext{
${ }^{9}$ Since employment ratio $E_{i}$ depends not only on participation rate $P_{i}$, but also on labour demand rate $D$, we assume that $E_{i}$ varies less than proportionally with $P_{i}$. For instance, $E_{i}$ may be approximately given by $D^{\chi_{i}} P_{i}^{\eta_{i}}$, where $\chi_{i}>0$ and $0<\eta_{i}<1$. This implies that a higher/lower $P_{i}$ leads to a lower/higher $E_{i} / P_{i}$, and hence a higher/lower $u_{i}$.

${ }^{10}$ Due to lack of work experience and investments in human capital, unemployment of youngsters can have adverse effects on the labour force participation and wages at a higher age. Schweitzer and Smith (1974) call this the 'persistence of the discouraged worker effect'.
} 
participation rate on the lagged participation rate as a result of lags in the working of explanatory variables such as the labour demand rate (cf. the parameter $\lambda$ in eq. (5) of Clark and Summers (1982) as distinct from the parameter $\beta_{1}$ of employment experience). On the other hand, a higher (lower) $P_{i t-1}$ may induce a lower (higher) $P_{i t}$ as a result of timing effects according to which individuals substitute labour supply in one period for labour supply in another period (Clark and Summers, 1982). Furthermore, a higher (lower) $P_{i t-1}$ also leads to a higher (lower) unemployment rate $u_{i t-1}$ (see the feedback effect above), and hence a lower (higher) $P_{i t}$ via the three discouraged worker effects explained before. Thus, these negative feedback effects of $P_{i t-1}$ on $P_{i t}$ counteract the positive feedback effects.

(iii) Yet other determinants of participation rate $P_{i}$ which change in a trend-like fashion are captured by a linear time trend. An important cause of the upward trend in female participation are cohort and period effects. Cohort effects for the Netherlands include the increasing level of education (Groot and Pott-Buter, 1993; Cörvers and Golsteyn, 2003), the decline in fertility (SCP, 1999), the more liberal social norms (Romme, 1990; Vendrik, 1993, 2003) with respect to paid employment, and more favourable child care and tax arrangements for later cohorts. As far as these changes were exogenous to changes in labour demand and employment (see above), they seem major sources of an autonomous time trend in female participation. The relevance of cohort effects for increasing labour force participation in different EU-countries, including the Netherlands, has recently been shown by Balleer et al. (2009).

(iv) The demand for male (female) workers is not only determined by total labour demand, but also negatively by female (male) labour supply since male and female labour supply are (imperfect) substitutes of each other. Such substitution between male and female labour supply will not only take place at the demand side of the labour market, but also at the supply side within families, as expressed in the added-worker effect (Prieto-Rodriguez and Rodriguez-Gutierrez, 2000; Stephens, 2002). Added-worker effects seem particularly important because of the prevalence of the breadwinner model in especially the 1970s and 1980s in the Netherlands as well as in other EU-countries (WRR, 2000; Balleer et al., 2009).

(v) In the last two decades major reforms in the area of disability and early retirement policies of the Dutch government took place which were not only motivated by rises in labour demand, but also by government-budget deficits (see, e.g., Gerards et al., 2008). Furthermore, during the whole period from 1969 there were tax and child care subsidy reforms in favour of female labour supply. Such policy reforms may have led to structural breaks in the dynamics of male and female labour force participation.

(vi) Finally, the changes in the total participation rates of men and women over the period considered may have been partially due to changes in the composition of the populations with respect to age, educational level, ethnicity, and household type. As far as the latter changes did not lead to trends in the development of the participation rates, and hence are not already captured by the 
autonomous trends (see (iv) above), they should have had separate effects on the dynamics of participation.

\section{The basic error correction models}

\subsection{Model selection}

To model and estimate the dynamics of male and female participation rates in response to changes in labour demand and autonomous trends we use error-correction models. Such models allow for a neat separation between short-run shock effects of changes in exogenous and lagged endogenous variables on the one hand, and adjustment of the endogenous variable to a long-run equilibrium on the other. To apply this model to the effects of changes in labour demand we need an exogenous or at most lagged endogenous indicator. As indicator we use the labour demand rate $D$, which has been defined in the previous section as total labour demand as a percentage of the potential labour force. As mentioned in the previous section, test results indicate that this measure of labour demand is at most lagged endogenous (see the next sections).

To use the time series of Section 2 for our model, we first determine the order of integration of the variables by performing tests for stationarity on the time series. Applying Augmented DickeyFuller tests to the time series of $\ln P_{m t}, \ln P_{f t}$, and $\ln D_{t}$ reveals that $\ln P_{m t}$ and $\ln D_{t}$ are integrated of order one (I(1)), whereas $\ln P_{f t}$ is trend-stationary (I(0)). When regressing series of this kind to each other, a common approach is using error-correction models that provide the possibility to estimate both longrun and short-run dynamics in the relationships between the series. However, for such models to produce consistent estimates the I(1) variables $\ln P_{m t}$ and $\ln D_{t}$ should be cointegrated. Applying the Johansen cointegration trace test to a vector error-correction model (VECM) with two equations for $\ln P_{m t}$ and $\ln D_{t}$ yields evidence for one cointegration relation between $\ln P_{m t}$ and $\ln D_{t}$ with a linear trend (for zero, one and two lags in the shock terms; see Appendix A). Next, exogeneity tests in the VECM with one cointegration relation provide mixed evidence for weak exogeneity of $\ln D_{t}$ to $\ln P_{m t}$ for the long-run parameters (Harris, 1995, pp. 63-65, 98-100). ${ }^{11}$ This means that in the equation for $\ln D_{t}$ the error-correction parameter (like $\rho_{m}$ in equation (1) below) is insignificant, implying that $\ln D_{t}$ does not converge in the long run to its cointegration relation with $\ln P_{m t}$. Thus, long-run causality runs from $\ln D_{t}$ to $\ln P_{m t}$, but not the reverse. In that case one can restrict to estimating the following single (conditional) ECM equation for $\ln P_{m t}$ :

$$
\Delta \ln P_{m t}=\alpha_{m}+\sum_{i=0}^{k} \beta_{m i} \Delta \ln D_{t-i}+\sum_{j=1}^{n} \gamma_{m j} \Delta \ln P_{m t-j}-\rho_{m}\left(\ln P_{m t-1}-\delta_{m} \ln D_{t-1}-\theta_{m} t\right)+\varepsilon_{m t},
$$

\footnotetext{
${ }^{11}$ The null hypothesis of weak exogeneity can be accepted for the optimal two lags and three and zero lags, but not at all for one lag. Inclusion of the second shock term $\triangle \ln D_{t-2}$ of labour demand into the VECM turns out to be critical for this sensitiveness. Weak exogeneity of $\ln D_{t}$ to $\ln P_{m t}$ and $\ln P_{f t}$ for the short-run parameters has also been tested with positive results (see Appendix A).
} 
where the parameters $\beta_{m i}$ and $\gamma_{m j}$ represent short-run shock effects of changes in labour demand and participation rate lagged, and $\rho_{m}$ is the parameter for the long-run correction of error $\ln P_{m t-1}-\delta_{m} \ln D_{t-1}-\theta_{m} t .{ }^{12}$ As usual, we choose the same value for the lag lengths $k$ and $n$ of the short-run shocks.

The equation for the trend-stationary variable $\ln P_{f t}$ for female participation can be written in error-correction form as

$$
\Delta \ln P_{f t}=\alpha_{f}+\sum_{i=0}^{k} \beta_{f i} \Delta \ln D_{t-i}+\sum_{j=1}^{n} \gamma_{f j} \Delta \ln P_{f t-j}-\rho_{f}\left(\ln P_{f t-1}-\theta_{f} t\right)+\varepsilon_{f t},
$$

where the parameters are analogous to those in equation (1). Note that in this case the error does not contain a long-run labour demand term $-\delta_{f} \ln D_{t-1}$ because of the stationarity of $\ln P_{f t}$.

The lag lengths $k=n$ that are most appropriate in equations (1) and (2) are determined by estimating the equations by OLS and finding the lag length for which the serial correlation in the residuals, as indicated by a Lagrange-Multiplier (LM) test (Patterson, 2000, p. 239), is insignificant or minimal, and for which an additional lag is rejected by a Wald test. Insignificant variables in the ECMs with these optimal lags are then eliminated one by one in order of their degree of insignificance, as indicated by their p-values.

\subsection{Results for male participation}

Estimations of equation (1) for male participation and lag length $k=n$ ranging from 0 to 5 indicate a significant linear trend term in the error. LM tests for serial correlations in the residuals reveal insignificant correlations for an ECM with two lags, and an additional lag is rejected by a Wald test. Eliminating insignificant variables then leads to an ECM for male participation the coefficients of which are presented in the left columns of Table 1. The t-ratios correspond to White's heteroscedasticity-consistent covariance matrix estimator.

Insert Table 1

The estimates in Table 1 suggest that there are significant and sizable short and long-run effects of labour demand as well as a small, but significant negative autonomous trend. The long-run elasticity of the male participation rate with respect to the labour demand rate is 0.58 . This implies that a change in the labour demand rate of one percent point leads in the long run to an average adjustment

\footnotetext{
${ }^{12}$ In general, the constant $\alpha_{m}$ consists of two components: one that corresponds to a constant in the expression for the long-run participation rate in the error term, and one that represents a short-run shock effect of changes in the time trend $(\Delta t=1)$. Since these two components cannot be separately identified in the estimations we take them together into one constant in front of the equation. We included the linear trend term in the error since the OLS regressions of the ADF equations for $\Delta \ln P_{m t}$ do not reveal a quadratic time trend, which suggests that there may be no corresponding time-linear shock effect either.
} 
of the male participation rate of $\left(\bar{P}_{m} / \bar{D}\right) 0.58=0.83$ percent point. ${ }^{13}$ This suggests that in the long run the male participation rate adjusted to changes in the labour demand rate to a high extent (as compared to the benchmark of 1 percent point; see Section 2). Furthermore, the trend coefficient -0.0039 implies an average autonomous long-run decline in the male participation rate of $0.0039 \bar{P}_{m}=0.33$ percent point per year. ${ }^{14}$ However, the speed of adjustment seems low, as indicated by the low estimate of the error-correction coefficient $\rho_{m}$. This estimate suggests that the male participation rate adjusted to its long-run equilibrium for only about $24 \%$ in a year. On the other hand, there is also a positive lagged endogenous shock term $0.32 \Delta \ln P_{m t-1}$, which tends to speed up the adjustment (since the shock effects of most explanatory variables are smaller than their long-run level effects). So, overall male participation seems to be moderately persistent.

Table 1 also shows a significant contemporaneous shock effect of $\ln D_{t}$ on $\ln P_{m t}\left(\beta_{m 0}\right)$. To exclude the possibility of reverse causality, we conducted a LM-test for weak exogeneity (Boswijk and Urbain, 1997), which indicated that $\ln D_{t}$ is weakly exogenous to $\ln P_{m t}$ for the short-run parameters (see Appendix A).

\subsection{Results for female participation}

Estimations of equation (2) for female participation and lag length $m=n$ ranging from 0 to 5 indicate a significant linear trend term in the error. The optimal lag is four with no significant serial correlation in the residual and an insignificant additional lag. Subsequent elimination of insignificant variables then leads to an ECM for female participation which is presented in the left columns of Table 2. Because there is some indication of second-order serial correlation in the residuals $(p=0.15)$, we present $\mathrm{t}$-values that are Newey-West-consistent.

Insert Table 2

Surprisingly, despite the absence of a long-run level effect of labour demand, the estimates in Table 2 show very significant and strong short-run shock effects of labour demand. The coefficient of the contemporaneous shock effect of $\ln D_{t}$ on $\ln P_{f t}\left(\beta_{f 0}\right)$ is unbiased since $\ln D_{t}$ is weakly exogenous to $\ln P_{f t}$ for the short-run parameters (see Appendix A). Remarkably, the shock effects alternate in sign, but their sum is positive and sizable, which indicates that a continuous and constant percentual rise (fall) in labour demand has a considerable positive (negative) effect on female participation. Similar shock effects of unemployment on female participation in the Netherlands have been found by Knoef (2006, Ch. 7) and Euwals et al. (2007). However, these capricious effects of changes in labour demand on female participation are only temporary since in the long run no permanent effects remain! There is

\footnotetext{
${ }^{13}$ An increase $\Delta D=1 \%$ (point), and hence $\Delta \ln D=(1 / D) \%$ implies $\Delta \ln P_{m}=(0.584 / D) \%$, and hence $\Delta P_{m}=\left(0.584 P_{m} / D\right) \%$. Inserting $\bar{P}_{m}=85.7$ and $\bar{D}=60.4$ for $P_{m}$ and $D$ then leads to $\Delta P_{m}=0.83 \%$.

${ }^{14} \mathrm{We}$ will give an explanation of this negative trend in Section 4.1.
} 
also a highly significant and sizable positive autonomous trend. Its coefficient 0.020 implies an average autonomous and strong long-run rise in the female participation rate of $0.020 \bar{P}_{f}=0.91$ percent point per year. ${ }^{15}$ We will discuss explanations of these results in later sections. The speed of adjustment to this long-run trend, as indicated by the estimate of the error-correction coefficient $\rho_{f}$, seems twice as high as for men. This estimate suggests that the female participation rate adjusted to its long-run equilibrium for about $50 \%$ in a year. Moreover, there are sizable positive feedback shock effects from changes in the one, three and four-years lagged female participation rate, which tend to speed up the adjustment to the long-run equilibrium path. So, female participation seems to be less persistent than male participation.

\section{Interaction between male and female participation}

\subsection{Results for male participation}

In the analysis for male participation, we concluded that an ECM with intercept and trend and a lag length of two gives the best fit to the data and significant and plausible parameter estimates. However, the presence of a downward exogenous time trend in this model calls for an explanation. This time trend accounts for the overall downward trend in male participation in combination with the overall upward trend in labour demand that can be detected in the time series of $\ln P_{m t}$ and $\ln D_{t}$ in Figure 1. In its turn, the upward trend in labour demand is related to the strong upward trend in female participation, which may partially be seen as a response to a secular upward trend in labour demand. At a first glance, this seems to be contradicted by the absence of long-run effects of labour demand on female participation which has been found in the previous section. However, this finding does not exclude that the effects of the upward trend in labour demand are included in the highly significant coefficient of the time trend in the long-run relation for female participation, whereas the insignificant coefficient of labour demand may only indicate insignificant effects of business-cycle variations of labour demand around its upward trend on female participation. Thus, the combination of a downward trend in male participation and an upward trend in labour demand suggests that the downward trend in male participation is due to a process of substitution of female for male participants to the labour force. In fact, if male and female employees would be perfect substitutes, male labour force participants face a labour demand which is given by total labour demand minus the labour supply of females. Moreover, substitution between male and female labour supply may take place not only at the demand side of the labour market, but also at the supply side within families, as expressed in the added-worker effect (Prieto-Rodriguez and Rodriguez-Gutierrez, 2000; Stephens, 2002). Such substitution effects may be made visible by including $\ln P_{f t}$ as an additional explanatory variable in the ECM for $\ln P_{m t}$.

\footnotetext{
${ }^{15}$ Since there is no significant quadratic time trend we assume that corresponding time-linear shock terms can be neglected.
} 
Since $\ln P_{f t}$ is an $\mathrm{I}(0)$ variable, it is weakly exogenous to $\ln P_{m t}$ for the long-run parameters and its one-year-lagged level can be added without problems to the error in the ECM for $\ln P_{m t}$ as an additional explanatory variable. Furthermore, shock terms of $\ln P_{f t}$ are added to the ECM for $\ln P_{m t}$. Since these additions change the ECM, we should again test whether $\ln D_{t}$ is weakly exogenous to $\ln P_{m t}$ for the long-run parameters. We tested this in a VECM with three equations for $\ln P_{m t}, \ln P_{f t}$ and $\ln D_{t}$ and two long-run relations, and again found mixed evidence for weak exogeneity of $\ln D_{t}$ to $\ln P_{m t}$ for the long-run parameters. ${ }^{16}$ Estimations for the extended equation for male participation and lag lengths $m=n$ ranging from 0 to 5 indicate insignificant coefficients of the linear trend and $\ln P_{f t}$ in the error. This is, of course, due to multicollinearity between these two variables. Since we are especially interested in the role of $\ln P_{f t}$ as the underlying explanatory factor of the time trend, we omitted the trend and obtained a significant coefficient of $\ln P_{f t}$. The optimal lag with insignificant serial correlation in the residual and insignificant additional lag turned out to be one. Eliminating insignificant variables then led to the estimates as presented in the middle columns of Table $1 .{ }^{17}$

These estimates show significant and considerable short and long-run effects of the female participation rate on the male participation rate, which have the expected negative signs. Since the time trend is now absent, this supports our conjecture that substitution effects from female on male participation account for the negative time trend in male participation. The long-run elasticity of the male with respect to the female participation rate of -0.20 implies that a rise (fall) in the female participation rate of one percent point leads in the long run to an average fall (rise) in the male participation rate of $\left(\bar{P}_{m} / \bar{P}_{f}\right) 0.20=0.38$ percent point at given labour demand rate. The contemporaneous and lagged short-run elasticities of the male with respect to the female participation rate sum up to a smaller effect, and the estimates for the other coefficients are similar to those for the basic model. The contemporaneous shock effects of $\ln D_{t}$ and $\ln P_{f t}$ can be considered as unbiased since both $\ln D_{t}$ and $\ln P_{f t}$ were found to be weakly exogenous to $\ln P_{m t}$ for the short-run parameters (Appendix A).

An issue which has not been considered so far is the stability of the parameters. Since there is not an apparent candidate for a breakpoint, we did Quandt-Andrews tests for the presence of an uncertain breakpoint. These tests and a further selection analysis strongly indicate that there is a breakpoint in the constant (see Appendix B). Including dummy variables $D U M_{94 t-1}$ and $\Delta D U M_{94 t}$ for this breakpoint into the estimations, where $D U M_{94 t}=0$ for $t \leq 1994$ and 1 for $t>1994$, we obtained the estimates presented in the last columns of Table $1 .{ }^{18}$ Since there is some indication of second-order

\footnotetext{
${ }^{16}$ Again the null hypothesis of weak exogeneity can be accepted for zero, two and three lags, but not for one lag. We assume two long-run relations since the single ECM for $\ln P_{f t}$ (eq. (2)) only has a significant time trend in the error, whereas the single ECM for $\ln P_{m t}$ also includes $\ln D_{t-1}$ and $\ln P_{f t-l}$ in the error. The exogeneity tests for zero, two and three lags indicate that male participation converges to only the latter long-run relation, while female participation converges to only the former one and labour demand converges to neither one (see Harris, 1995, Ch. 5).

${ }^{17}$ We did not drop the insignificant $\Delta \ln P_{f t-1}$ and $\Delta \ln P_{m t-1}$ terms since this led to a much lower D-W and more serial correlation.

${ }^{18}$ We tested for cointegration of $\ln P_{m t}$ and $\ln D_{t}$ and weak exogeneity of $\ln D_{t}$ to $\ln P_{m t}$ for the long-run parameters (WELP) in the presence of this breakpoint in a VECM with three equations for $\ln P_{m t}, \ln P_{f t}$ and $\ln D_{t}$. The Johansen tests indicated that there is at least one cointegration relation between $\ln P_{m t}$ and $\ln D_{t}$ conditional on
} 
correlation in the residual $(\mathrm{p}=0.07)$, the t-values are based on Newey-West-corrected standard errors. The jump in the long-run level of male participation that is implied by the coefficient 0.058 of $D U M_{94 t-1}$ is sizable $\left(0.058 P_{m 1993}=4.61\right.$ percent point; see Figure 2$)$. It can be associated with two major reforms in the area of Dutch disability policies, namely the 1992 Act on Reducing Disability Volume and the 1993 Act on Reducing Disability Claims (Oorschot and Boos, 2001; Gerards et al., 2008). Both laws were aimed to reduce the number of disability-benefit claimants, and indeed caused a considerable downturn in the numbers of disabled men and women after 1993, which for men stabilized on a lower level (see the next section for the case of women). In addition, in later years arrangements for early retirement (like the so-called VUT) were made less attractive, which led to a strong rise in the labour force participation in the age group of 55 to 65 years (CBS, 2004). Our finding of a very significant exogenous breakpoint in male participation in 1994 strongly suggests that these policy changes cannot be merely explained as a reaction to the rise in labour demand after 1994, but had exogenous causes. This is consistent with the disability reforms being motivated by the urgent need to reduce the rising burden of the disability-benefits expenditures for the government budget (see, e.g., Gerards et al., 2008). According to Figure 2, the reforms had the effect of bringing the longlasting decline in male participation since the 1960s to a halt and making it adjust to a permanently higher level.

Insert Figure 2

This adjustment was reinforced by the strong rise in labour demand after 1994, but the estimate 0.37 of the long-run elasticity of male participation rate with respect to labour demand rate in Table 1 implies that the long-run effect of this rise $\left(\left(\bar{P}_{m} / \bar{D}\right) 0.37=0.52\right.$ percent point on average for each one percent point rise in the labour demand rate) was considerably smaller than what is suggested by the higher long-run-elasticity estimates in the ECMs without breakpoint (left and middle columns of Table 1). On the other hand, the short and long-run substitution effects of the female on the male participation rate are now stronger. In particular, the long-run elasticity -0.29 implies an average fall (rise) in the male participation rate of $\left(\bar{P}_{m} / \bar{P}_{f}\right) 0.29=0.53$ percent point for each one percent point rise (fall) in the female participation rate. Furthermore, error-correction coefficient $\rho_{m}=0.47$ has doubled, thus raising the adjustment speed. However, this rise is counteracted by the now negative lagged endogenous shock term $-0.22 \Delta \ln P_{m t-1}$, which tends to suppress the adjustment speed.

\subsection{Results for female participation}

A puzzling finding in the basic ECM for female participation is the absence of a long-run level effect of labour demand. May this, as the mirror image of the substitution effect from female on male

$\ln P_{f t}, T$ and $D U M_{94 t}$, and the $\mathrm{H}_{0}$ of WELP of $\ln D_{t}$ to $\ln P_{m t}$ could be accepted for the optimal one lag, but not for two lags. See for evidence of weak exogeneity of $\ln D_{t}$ and $\ln P_{f t}$ to $\ln P_{m t}$ for the short-run parameters in the presence of the breakpoint Appendix A. 
participation, be related to a substitution effect from male on female participation? More specifically, may it be the case that the zero level effect of labour demand on female participation is the net result of a direct positive effect of labour demand on female participation and a counteracting indirect effect of labour demand on female participation via its effect on male participation and ensuing substitution of male for female participation. This question is addressed in this section by including $\ln P_{m t}$ as an additional explanatory variable in the ECM for $\ln P_{f t}$.

However, $\ln P_{m t-l}$ cannot simply be added to the error in equation (2) since it is not a stationary $\mathrm{I}(0)$ variable. As we also want to include $\ln D_{t-1}$ in the error to account for the direct labour demand effect alluded to above, a solution is to insert the cointegrating linear combination of $\ln P_{m t}$ and $\ln D_{t}$, as determined in the ECMs for $\ln P_{m t}$, as an additional variable into the error in equation (2). This cointegrating combination is $\mathrm{I}(0)$, and moreover has the desired property of implying a zero net level effect of labour demand on female participation (see below). It is taken from the extended ECM for $\ln P_{m t}$ with breakpoint in Table 1, as being the best-fitting ECM. Since this cointegration relation is conditional on the breakpoint dummy $D U M_{94 t-1}$, we include this dummy in the cointegrating combination in the error as well. Thus, we insert $\ln P_{m t}-0.370 \ln D_{t-1}-0.0578 D U M_{94 t-1}$ as an additional variable into the error in equation (2), and add corresponding shockterms of $\ln P_{m t}, \ln D_{t}$ and $D U M_{94 t}$ as well.

In the VECM with three equations for $\ln P_{m t}, \ln P_{f t}$ and $\ln D_{t}$ and two long-run relations that has been mentioned in footnote 18, we similarly found evidence for weak exogeneity of $\ln P_{m t}$ and $\ln D_{t}$ to $\ln P_{f t}$ for the long-run parameters. Estimations of the extended ECM for female participation and lag lengths $m=n$ ranging from 0 to 7 indicated a significant linear trend term in the error and an optimal lag of four. Since there was still some indication of serial correlation $(p=0.12)$, subsequent elimination of insignificant variables was based on Newey-West-corrected standard errors. This led to the estimates as presented in the middle columns of Table 2. We also did Quandt-Andrews tests for the presence of an additional breakpoint, but did not find evidence for that.

Strikingly, these estimates now show strong long-run effects of labour demand as well as male participation on female participation with the expected signs. ${ }^{19}$ This suggests that indeed a strong substitution effect from male on female participation counteracts a strong labour-demand effect on female participation. Moreover, since there is no long-run labour-demand effect on female participation in the basic model without male participation, the substitution effect from male on female participation should be so strong as to imply a zero 'net' effect of labour demand on female participation in the basic model. This holds as a result of the inclusion of the cointegrating combination of $\ln P_{m t}$ and $\ln D_{t}$ in the long-run relation. A change in the labour demand rate of one percent point leads in the long run to a change in the cointegrating combination $\ln P_{m t}-0.370 \ln D_{t-1}$ -

\footnotetext{
${ }^{19}$ Although the cointegration restrictions on $\ln D_{t-1}$ and $D U M_{94 t-1}$ do not allow the calculation of standard errors and t-statistics for the coefficients of these variables, we can approximate the t-values by the t-values of $\ln D_{t-1}$ and $D U M_{94 t-1}$ in the corresponding unrestricted ECM. Estimation of this ECM yields coefficients 0.701 with tvalue 14.64 for $\ln D_{t-1}$ and 0.093 with t-value 6.59 for $D U M_{94 t-1}$. These coefficients do not significantly differ from those in the right columns of Table 2 , and the restriction is accepted by a Wald test $(p=0.26)$. We report the coefficients for the restricted ECM since this ECM is exactly consistent with stationarity of $\ln P_{f t}$.
} 
$0.0578 D U M_{94 t-1}$ of $0.370-0.370=0$ percent point, and hence to a zero 'net' effect on female participation. This zero 'net' effect is the result of a direct and an indirect effect on female participation. Estimate 0.66 of the long-run elasticity of female participation rate with respect to labour demand rate implies that the direct long-run effect of a rise in the labour demand rate of one percent point is an average rise in the female participation rate of $\left(\bar{P}_{f} / \bar{D}\right) 0.66=0.50$ percent point at given male participation rate. On the other hand, there is also an indirect effect as a result of the long-run rise in the male participation rate of 0.52 percent point, which in turn, by substitution, leads to an average fall in the female labour participation rate by $\left(\bar{P}_{f} / \bar{P}_{m}\right) 1.77=0.96$ times $0.52=0.50$ percent point. Thus, this indirect substitution effect from male on female participation indeed fully compensates for the direct effect of labour demand on female participation as supposed above. ${ }^{20}$

This result also suggests that this substitution effect occurs not only at the demand side of the labour market, but also at the supply side within families in the form of the added-worker effect since otherwise the compensation of the direct effect of labour demand on female participation by the indirect substitution effect would be expected to be only partial (some part of the change in labour demand would be absorbed by a change in female participation). In fact, assuming that male and female labour are imperfect substitutes according to a Cobb-Douglas function in the long run, it is easily shown that the relative amount by which coefficient -1.772 of $\ln P_{m t-1}$ in Table 2 exceeds coefficient 0.655 of $\ln D_{t-1}$ determines a lower bound for the relative share of the added-worker effect in the total substitution effect. More specifically, Appendix $\mathrm{C}$ suggests that the added-worker effect amounts to between 63 and $82 \%$ of the total substitution effect. Such a large added-worker effect in the Dutch context may be explained by the strong prevalence of the male-breadwinner model in especially the 1970s and 1980s: when in that model the male breadwinner became disabled, after some time his spouse may have started to search for a job to raise the family income. Reversely, there could also have occurred a much smaller added-worker effect when female breadwinners left the labour market.

A reasoning analogous to that for the effects of labour demand changes holds with respect to the effects of the disability policy reforms in 1992 and 1993 (see the previous section) on female participation. Although there was a large direct effect of $0.102 P_{f 1993}=5.33$ percent point on the longrun level of female participation, this was fully compensated by a substitution effect from the rising male participation as a result of the reforms. Again this holds as a result of the inclusion of the cointegrating combination of $\ln P_{m t}$ and $\ln D_{t}$ in the long-run relation. The policy reforms led in the long run to a change in the cointegrating combination $\ln P_{m t}-0.370 \ln D_{t-1}-0.0578 D U M_{94 t-1}$ of 0.0578 $0.0578=0$ percent point, and hence to a zero 'net' effect on female participation. This is consistent with the data for the percentage of the female working age population receiving disability benefits (CBS, 2004) indicating a considerable drop after 1993, but a resumption of the structural rise from

\footnotetext{
${ }^{20}$ Conversely, there is no long-run compensating substitution effect from female on male participation since the long-run net effect of a change in labour demand on female participation is zero.
} 
1995 onwards. This is illustrated by Figure 3 indicating a considerable jump in the long-run female participation rate between 1993 and 1994, but a gradual return to the long-run trend after these years.

Insert Figure 3

Considering now the short-run effects on female participation, we see that, just like the longrun substitution effect, the short-run substitution effects of male on female participation are large. The short-run effects of labour demand on female participation are sizable as well, but somewhat smaller than those in the basic ECM. The contemporaneous shock effects of $\ln D_{t}$ and $\ln P_{m t}$ can be considered as unbiased since both $\ln D_{t}$ and $\ln P_{m t}$ were found to be weakly exogenous to $\ln P_{f t}$ for the short-run parameters (Appendix A). ${ }^{21}$ Error-correction coefficient $\rho_{f}=0.56$ is a little higher than that in the basic model. On the other hand, the sum of the positive feedback shock effects from changes in the one-year and three-years lagged female participation rate, which tend to speed up the adjustment to the long-run equilibrium path, is considerably lower than the corresponding sum in the basic ECM. Thus on the whole, the speed of adjustment seems comparable and again moderate.

Overall, the results strongly suggest that in the Netherlands the supply reactions of men to cyclical variations in labour demand and policies completely pushed away any supply reactions of women (in line with what feminists tend to assert). Nevertheless, Dutch women continued to increase their labour force participation as a result of the overall upward trend in labour demand (see the previous section) and other factors, as expressed by the strongly significant trend coefficient 0.0094 . In addition, this rise in female participation suppressed $\ln P_{m t}$ as a result of substitution of female for male participation, which feeded back on a further rise in $\ln P_{f t}$, which further suppressed $\ln P_{m}$, etc. towards a new equilibrium for male and female participation. Deriving this equilibrium for $\ln P_{f t}{ }^{22}$ yields a coefficient 0.0190 of $T$ in the long-run equation for $\ln P_{f t}$, which corresponds to the coefficient 0.0197 of $T$ in the basic (reduced-form) ECM. Thus, about one half of this time trend in $\ln P_{f t}((0.0190-$ $0.0094) / 0 / 0190$ ) is due to the overall upward trend in labour demand in combination with a reinforcing feedback of the rise in female participation on itself via substitution of female for male participation. Since the estimates for the basic ECM imply that female participation did not respond to the business cycle in the long run (Section 3.3), these upward-trend effect of labour demand and reinforcing substitution effects may primarily have taken place in sheltered sectors that are less sensitive to the

\footnotetext{
${ }^{21}$ On the other hand, the strong significance of the contemporaneous substitution effects in the optimal ECMs for $\ln P_{m t}$ and $\ln P_{f t}$ strongly suggests that $\ln P_{m t}$ and $\ln P_{f t}$ may as well be regarded as mutually endogenous for the short-run parameters. Therefore, we also carried out FIML and LIML estimations of the short-run parameters in systems of two ECM-equations for $\ln P_{m t}$ and $\ln P_{f t}$ with fixed long-run parameters. This yielded unreliable results for the FIML estimations and insignificant estimates for the LIML estimation with a structural equation for $\ln \mathrm{P}_{m t}$, but a more reliable, weakly significant estimate -2.25 of the contemporaneous substitution effect of $\ln \mathrm{P}_{m t}$ on $\ln \mathrm{P}_{f t}$ for the LIML estimation with a structural equation for $\ln _{f t}$ (with an insignificantly small lagged shock effect of $\ln \mathrm{P}_{m t}$ on $\ln \mathrm{P}_{f t}$ ). This estimate is not significantly different from estimate -1.55 (or its sum -2.09 with the lagged shock effect) in the single ECM in Table 2, and thus confirms the reliability of the latter estimate.

${ }^{22}$ The equilibrium can be derived by substituting $-0.285 \ln P_{f t}$ for the cointegrating combination $\ln P_{m t^{-}}-0.370 \ln D_{t-1^{-}}$ $0.0578 D U M_{94 t-1}$ (as implied by the long-run relation for $\ln P_{m t}$ in Table 1) in the long-run relation for $\ln P_{f t}$ in Table 2.
} 
business cycle like the care and educational sectors (cf. Borghans and De Grip, 2005). In these sectors the rise in female participation may have discouraged male participation by suppressing wages and/or raising unemployment, and may thus have enhanced its "own" labour demand.

\subsection{Sources of persistence effects}

In Section 2 it has been shown that several causal mechanisms may underlie the dynamic relations between the main variables, which have been estimated by the error-correction models in this study. An interesting question may then be whether it is possible to identify these underlying causal mechanisms from the coefficient estimates of the ECMs. We should then formulate a structural model which is consistent with the estimated ECMs and the parameters of which are identifiable from the estimated ECM coefficients. The most obvious candidates for such a structural model explain the dynamics of the participation rates as the effects of distributed lags of the explanatory variables with exponentially declining weights. An interesting structural model which is consistent with the estimated extended ECM equation (1) with breakpoint for male participation (see the right columns of Table 1), is formulated in Appendix D.

This structural model yields, among other things, an expression for adjustment parameter $\rho_{m}=0.47$ (Table 1) in terms of structural parameters for the positive work experience and bandwagon feedbacks and negative timing and discouraged-worker feedbacks from the lagged participation rate (see Section 2) as well as a parameter for the speed of declining of the weights of the distributed lags of the explanatory variables (like the parameter $\lambda$ of Clark and Summers (1982)). This expression implies that in the long-run the persistence-reducing effect of the negative feedbacks via timing and discouraged-worker effects just dominates the persistence-increasing effect of the positive bandwagon and work experience feedbacks, leaving the distributed lags in the working of the explanatory variables as the decisive source of persistence in the male participation rate. For the extended ECM for female participation a similar underlying distributed-lags model can be found, which, just as for male participation, implies that the distributed lags in the working of the explanatory variables are the decisive source of persistence in the female participation rate.

In addition to the persistence effects of habit and human capital formation that work via a lower speed of adjustment towards the long-run equilibrium path and lagged shock terms of the endogenous participation rate, there may also occur hysteresis effects of habit and human capital formation in the form of asymmetric responses to rises and falls in exogenous variables like labour demand (see Vendrik (1993) for the distinction between the former and latter effects). For example, Darby et al. (2001) argue that especially older workers may not only be temporarily discouraged from participating in the labour market in a period of recession, but also permanently to the extent of causing a larger adjustment of participation to negative shocks in the cyclical component of business sector GDP than to positive shocks. They find evidence for such an asymmetry in the responses of older women. Therefore, in our extended ECMs with breakpoint we tested for different effects of 
upward and downward shocks in labour demand on male and female participation, but we did not find significant asymmetries. ${ }^{23}$ However, there may also occur a less permanent, but still persistent discouragement of participation due to a reduction of contemporaneous positive labour demand effects by erosion of human capital and working habits in a preceding recessionary period (cf. Schweitzer and Smith, 1974). This can be modelled approximately by an interaction term $\phi_{i} \Delta \ln P_{i t-1} \operatorname{sgn}\left(\Delta \ln D_{t}\right) \Delta \ln D_{t}$, where $i=m, f, \phi_{i}$ is a positive parameter, and $\operatorname{sgn}\left(\Delta \ln D_{t}\right)=1$ if the sign of $\Delta \ln D_{t}$ is positive and -1 if the sign of $\Delta \ln D_{t}$ is negative. This interaction term describes that a positive (negative) shock in labour demand has a smaller effect on current participation if there was a stronger fall (rise) in participation in the previous year. On the one hand, a previous-year fall in participation is supposed to represent the negative effect of erosion of human capital and working habits while on the other hand a previous-year rise in participation stands for the positive effect of increasing human capital and working habits (persistent encouraged-worker effect). However, this interaction term did not receive significant coefficients either.

\section{Decomposition analysis}

To give a better insight into the relative magnitudes of the effects estimated in the ECMs this section presents a decomposition analysis. Moreover, this analysis allows us to include the participation effects of changes in the composition of the population with respect to variables like age and educational level. These effects were lacking in the analysis so far since data on personal and household characteristics is not available for the total period between 1969 and 2004, but only for the last eleven years of the estimation period, i.e. 1994-2004 (via the website of Statistics Netherlands: statline.cbs.nl).

In 1994 the economy in the Netherlands started to recover from a recession. The economy achieved a peak in 2001 and from then on a new downturn set in. Between 1994 and 2001 the labour demand rate rose from 57.7 to $68.8 \%$, and next it fell to $66.3 \%$ in 2004 . As a result, the unemployment rate declined from $8.3 \%$ in 1994 to $3.3 \%$ in 2001, and next increased to $6.2 \%$ in 2004 . Thus, the period between 1994 and 2004 successively comprises an upturn and a downturn of the economy. This allows us to conduct a decomposition analysis of both the model and compositional effects on male and female participation for the upturn and downturn period separately. Such an analysis sheds light on the contributions of the various determinants to the development of the participation rates in these different phases of the business cycle.

Tables 3 and 4 show the decompositions of the changes in participation rates for men and women in the two sub-periods. To calculate the effects in the model simulation we used the estimated extended equations (1) and (2) with breakpoint (see Tables 1 and 2). We simulated conditional

\footnotetext{
${ }^{23}$ Darby et al. (2001) do not make a distinction between asymmetric shock and level effects. In fact, their estimated asymmetries seem to imply strange hysteresis loops of long-run levels of participation rates which jump towards higher levels at the turning points of the estimated cycles (thus suggesting strong encouragedworker effects at these points!?).
} 
predictions of labour force participation by keeping successively more explanatory variables constant at the starting values of the two sub-periods, i.e. 1994 and 2001, respectively. In this way we could calculate the contribution of each explanatory variable(s) to the total predicted change in participation rate in each sub-period as the difference between the predicted participation rate when some other explanatory variables were kept constant at their initial values and the predicted participation rate when these explanatory variables plus the variable of interest were kept constant. To calculate the effects of the changes in population composition we kept the male and female labour force participation rates in the different categories of age classes (five-year classes), educational levels (seven levels), ethnical background (seven groups) and household types (seven types) constant at the initial values of 1994 and 2001. The resulting difference between the initial participation and the calculated participation at the end of the sub-period can be attributed to the change in the population composition for the respective population characteristic.

Insert Tables 3 and 4

From Tables 3 and 4 it can be concluded that the total effects of the explanatory variables in the model simulation are much more important than the total effects of changes in the population composition. The total actual increase in labour force participation between 1994 and 2001 is 4.3\% and $8.9 \%$ for men and women, respectively. The effect of labour demand on participation is one of the most important factors. Between 1994 and 2001 increasing labour demand had a strong positive impact on participation. As explained before, this mainly represents encouraged worker effects, including people being more eager to find a job because of better chances and higher wages on the labour market, young people leaving school earlier, older people postponing retirement, etc. Moreover, these effects may have been reinforced by bandwagon and work experience effects. The impacts are negative between 2001 and 2004 since labour demand was falling during these years. In these years discouraged worker effects play an important role.

Another important factor stimulating participation from 1994 onwards was the large jump in the long-run participation rate between 1993 and 1994. This jump was mainly due to important changes in Dutch social-security policies, in particular the reform in disability law in 1993 that has been mentioned in Section 4.1. Since then it was more difficult and less attractive to withdraw from the labour market. However, it took some time for the actual participation rate to catch up with the long-run level. After 2001 the reforms had no longer an effect on the participation rate of women, but they prevented the male participation rate from falling too much as a result of the recession.

Tables 3 and 4 reveal strong substitution effects between men and women. Rising female labour supply led to a downward pressure on male participation. The effect is estimated at $-4.2 \%$ points between 1994 and 2004. The growth in female participation was strongly curbed (-7.1\%) by rising male participation before 2001 , and slightly stimulated $(0.4 \%)$ by declining male participation after 2001. Before 2001 the substitution effect from male participation almost fully compensated the 
positive labour demand effect, thus making the net labour demand effect on female participation small. The decomposition analyses clearly show that we should not abstract from these substitution effects when modeling changes in male and female labour force participation.

Only for women we have estimated a significant autonomous trend in labour force participation. This trend has a strong positive effect in both sub-periods. As mentioned earlier, an important source of the autonomous trend is more progressive social norms of younger birth cohorts. Participation increases as younger, more participating cohorts of women enter the labour market and older cohorts pass the 65 years-of-age threshold. Growth in labour force participation between 1994 and 2001 was strongest for women between 45 en 54 years old. The more progressive norms of these females were probably developed when they were 15 to 25 years old, so 30 years earlier. Figures from the Netherlands Institute for Social Research (SCP, 1999) indicate that between 1964 and 1971 (the roaring 60s) the public opinion on working by married women with school-going children changed dramatically. Whereas in $196584 \%$ of the Dutch population disapproved working by these women, this percentage rapidly declined to $44 \%$ in 1971 . Afterwards the decline went slower, down to $16 \%$ in 1995. Changing social norms may have influenced the social norms of younger cohorts during the whole period between 1965 and 1995, and may even have generated cohort effects on labour force participation many years after $1995 .^{24}$ After 1995 the trend towards more progressive social norms more or less stopped, or even turned around somewhat (SCP, 2002).

A factor which only had a considerable effect on female participation after 2001 are the feedback shock effects from before the beginning of the period. Apparently, the changes in the oneyear and three-years lagged female participation rate before 2001 still had a strongly positive reinforcing impact on the rise in female participation after 2001 (see Section 4.2).

Although the net impact of the changing population composition on participation was much smaller than the net impact of the estimated model effects, in particular age and educational level had relatively large effects, which work in opposite directions to each other. On the one hand, the increase in the educational level, in particular of women, had a positive effect on labour force participation since the higher the level of education, the stronger the incentives to work. On the other hand, the greying of the population decreased participation since older age classes on average participate less. The same holds with respect to the rising share of most ethnical minorities in the Netherlands.

Finally, after adding up the estimated model effects and those of the changes in the composition of the population we find a difference with the actual increase in participation. This is the so-called residual that is virtually zero for male participation between 1994 and 2001 and for female participation between 2001 and 2004. In the other two decomposition cases the total impact of the model and population effects is overestimated relatively to the actual changes in labour force participation. In the case of female participation between 1994 and 2001, this may be (partially) attributed to a part of the autonomous trend being due to a rise in educational level. In the case of male

24 See De Neubourg and Vendrik (1994) and Vendrik (2003a) for behavioural models of the impact of social norms on labour supply. 
participation between 2001 and 2004, the overestimation of the total decrease in participation may partially come from the possibility that a considerable part of the negative participation effect of greying worked via a decline in labour demand (because of higher wage costs).

\section{Summary and concluding remarks}

This study investigated the extent and speed of dynamic adjustment of labour supply to changes in labour demand, government policies and autonomous trends. Our examination began with an extensive analysis of six basic impacts on male and female labour force participation and the various mechanisms underlying these impacts. We then incorporated these impacts into dynamic error-correction models of male and female participation. To estimate these models we used time series for the Netherlands between 1969 and 2004. Stationarity, cointegration and exogeneity tests indicated that we could use single-equation ECMs for our estimations. We first analysed basic ECMs without substitution effects between male and female labour supply. For male participation we found significant and sizable short and long-run effects of labour demand as well as a small, but significant negative autonomous trend. The long-run elasticity of the male participation rate with respect to the labour demand rate suggests that in the long run the male participation rate adjusted to changes in the labour demand rate to a high extent. Moreover, male participation was found to be moderately persistent. For female participation in the basic model, we found significant and sizable short-run shock effects of labour demand, but no significant long-run level effect of labour demand and a strong positive autonomous trend. Furthermore, female participation was found to be less persistent than male participation.

However, when we included female and male participation as additional explanatory variables in the male and female ECMs, respectively, we obtained significant substitution effects of female and male participation on each other. For male participation the substitution effects from female participation account for the negative trend in the simple ECM, while for female participation the substitution effects from male participation counterbalance labour demand effects that are now significant. In addition, we found very significant breakpoints in male and female participation at 1994. From 1993 to 1994 the long-run levels of male and female participation rates exhibit a large upward jump, to which the actual participation rates gradually adjusted in the ensuing years. We interpret these adjustments as the result of exogenous participation-promoting policies by the Dutch governments in that period. Finally, the long-run elasticity of the male participation rate with respect to the labour demand rate now suggests that in the long run the male participation rate adjusted to changes in the labour demand rate for only about a half. Furthermore, both male and female participation were found to be moderately persistent.

Since the beginning of this millennium one of the important goals of the Dutch and other governments of the European Union has been to further increase the labour force participation of men and women (WRR, 2000; European Council, 2000). Striving for higher participation rates could 
compensate for the adverse impact of the greying labour force. Our decomposition analyses for the period between 1994 and 2001 showed that the Netherlands were already on their way to achieve higher rates of labour force participation. In this respect five important points can be raised.

First of all, labour demand has a strong impact on labour supply. Male participation rates adapt to changes in labour demand. However, they do so only partially. Furthermore, the long-run development of female participation rates does not respond to cyclical variations in labour demand, but still reacts to the overall upward trend in labour demand and substitutes for male participation in sheltered sectors. The upturn of the economy and the strong rise in labour demand since 1994 were to a large extent responsible for increasing participation rates of both men and women. Encouraged worker effects may have been reinforced by work experience and bandwagon effects. The upturn of the economy till 2001 as well as the downturn since 2001 shows that economic growth stimulates participation, but the incomplete adaptation of labour supply to rises in labour demand calls for further flexibilisation of the labour market (see also ECB, 2008).

Secondly, policies stimulating female and male participation may go at the expense of each other. Our analysis clearly shows that it is very important to account for substitution effects between men and women in the labour market. Otherwise the net impact of participation-promoting policies may be overestimated. Thirdly, important changes in social-security policies, like the reform in disability law in 1993, take some years before they are fully reflected in higher participation levels. After 2001 the earlier reforms in Dutch social-security policies had no longer an effect on the participation rate of women, but they seem to have prevented the male participation rate from falling too much as a result of the recession.

Fourthly, changes in social norms with respect to, e.g., the issue of work-life balance can have an important impact during the decades to follow, as has been illustrated by the dramatic change in public opinion on working by married women with school-going children in the 1960s. The change towards more progressive social norms contributed to a strong positive trend in female participation in the Netherlands. Finally, we showed that the net impact of the changing population composition on participation was relatively modest. Nevertheless, the increase in educational level, in particular of women, had a clear positive effect on labour force participation. On the other hand, the greying of the population decreased participation. This shows that investing in education raises participation in the long run, and that particular attention should be given to policies that promote the participation of older men and women.

\section{Acknowledgements}

We would like to thank Bram Smeets and Niels Muselaers for their econometric support to the tests and estimations, Jean-Pierre Urbain, Arnaud Dupuy and Thomas Ziesemer for econometric advise, and Lex Borghans and Joan Muysken for helpful comments. 


\section{References}

Akerlof, G.A. (1980), A Theory of Social Customs, of Which Unemployment May Be One Consequence, Quarterly Journal of Economics, Vol. 94, pp. 749-775.

Andrews, D.W.K. (1993), Tests for Parameter Instability and Structural Change with Unknown Change Point, Econometrica, Vo. 61, No. 4, pp. 821-856.

Autor, D.H. and M.G. Duggan (2003), The Rise in the Disability Rolls and the Decline in Unemployment, Quarterly Journal of Economics, Vol. 118, pp. 157-205.

Balleer, A., R. Gómez-Salvador and J. Turunen (2009), Labour Force Participation in the Euro Area, A Cohort Based Analysis, Working Paper Series No. 1049, European Central Bank, Frankfurt am Main.

Bergmann, B.R. (1974), Occupational Segregation, Wages and Profits When Employers Discriminate by Race or Sex, Eastern Econonomic Journal, Vol. 1, Nos. 1-2, pp. 103-110.

Borghans, L. and A. de Grip (2005), Beroepensegregatie op de Nederlandse arbeidsmarkt: een economisch perspectief, in: H. Galesloot (ed.), De Glazen Muur, Essays about Occupational Segregation, Ministry of Social Affairs and Employment, The Hague, pp. 9-23.

Borghans, L. and L. Groot (1999), Educational Presorting and Occupational Segregation, Labour Economics, Vol. 6, pp. 375-395.

Börsch-Supan, A. (1998), Incentive Effects of Social Security on Labor Force Participation: Evidence in Germany and across Europe, National Bureau of Economic Research, NBER Working Paper No. 6780, Cambridge Mass.

Boswijk, P. (1994), Testing for an Unstable Root in Conditional and Structural Error Correction Models, Journal of Econometrics, Vol. 63, pp. 37-60.

Boswijk, P. (1998), Unit Roots and Cointegration, Lecture Notes, Universiteit van Amsterdam.

Boswijk, P. and H.P. Franses (1992), Dynamic Specification and Cointegration, Oxford Bulletin of Economics and Statistics, Vol. 54, pp. 369-981.

Boswijk, P. and J.-P. Urbain (1997), Lagrange-Multiplier Tests for Weak Exogeneity: A Synthesis, Econometric Reviews, Vol. 16(1), pp. 21-38.

CBS (2004), Labour Force Survey, Statistics Netherlands, Voorburg.

Clark, K.B. en L.H. Summers (1982), Labour Force Participation: Timing and Persistence, Review of Economic Studies, Vol. 49, pp. 825-844.

Cörvers, F. en B. Golsteyn (2003), Changes in Women's Willingness to Work in a Tightening Labour Market: The Impact of Preferences, Wages and Individual Characteristics, ROA-R-2003/5E, Maastricht University.

CPB (2001), Arbeidsparticipatie van Vrouwen, CPB Notitie, The Hague.

CPB (2005), Centraal Economisch Plan 2005, Centraal Planbureau, The Hague. 
Darby, J., R.A. Hart and M. Vecchi (2001), Labour Force Participation and the Business Cycle: A Comparative Analysis of France, Japan, Sweden and the United States, Japan and the World Economy, Vol. 13, pp. 113-133.

De Neubourg, , C. and M. Vendrik (1994), An Extended Rationality Model of Social Norms in Labour Supply, Journal of Economic Psychology, Vol. 15, pp. 93-126.

ECB (2008), Labour Supply and Employment in the Euro Area, Development and Challenges, Occasional Paper Series No. 87, Frankfurt am Main.

Eckstein, Z. and K.I. Wolpin (1989), Dynamic Labour Force Participation of Married Women and Endogenous Work Experience, Review of Economic Studies, Vol. 56, pp. 375-390.

European Commission (2001), Employment in Europe 2001, Luxembourg.

European Council (2000), Presidency Conclusions, March 23-24, Lisbon.

Euwals, R., D. Van Vuuren, and R. Wolthoff (2004), Prepensioen en Arbeidsparticipatie Ouderen, CPB Memorandum 101, Den Haag.

Euwals, R., M. Knoef and D. van Vuuren (2007), The Trend in Female Labour Force Participation: What Can be Expected for the Future?, IZA discussion paper 3225, Bonn.

Fernández, R. (2007), Culture as Learning: The Evolution of Female Labor Force Participation over a Century, Working paper, New York University.

Gerards, R., M. Müllers and J. Muysken (2008), Institutional Reforms that Really Matter: OECD Institutional Indicators vs. Dutch Reform History, CofFEE-Europe Working Paper, Maastricht University.

Groot, W. and H. Pott-Buter (1993), Why Married Women's Labor Supply in the Netherlands Has Increased, De Economist, Vol. 141, pp. 238-255.

Hansen, B.E. (1992), Tests for Parameters Instability in Regressions with I(1) Processes, Journal of Business \& Economics Statisitics, Vol. 10, No. 3, pp. 321-335.

Harris, R.I.D. (1995), Using Cointegration Analysis in Econometric Modelling, Prentice Hall Harvester Wheatsheaf.

Hassink, W.H.J., J.C. van Ours en G. Ridder (1997), Dismissal Through Disability, De Economist, Vol. 145, pp. 24-46.

Juhn, C. (1992), Decline of Male Labor Market Participation: The Role of Declining Market Opportunities, Quarterly Journal of Economics, Vol. 107, pp. 79-121.

Kapteyn, A. en K. de Vos (1997), Social Security and Retirement in the Netherlands, National Bureau of Economic Research, NBER Working Paper No. 6135, Cambridge Mass.

Knoef, M. (2006), An APC Analysis of Female Labour Force Participation in the Netherlands, MA thesis, Tilburg University.

Koning, P. and D. van Vuuren (2007), Hidden Unemployment in Disability Insurance, Labour, Vol. 21, pp. 611-636.

Koning, P.W.C. and D.J. van Vuuren (2009), Disability Insurance and Unemployment Insurance as Substitute Pathways, forthcoming in Applied Economics. 
Leibenstein, H. (1950), Bandwagon, Snob, and Veblen Effects in the Theory of Consumer Demand, Quarterly Journal of Economics, Vol. 64, pp. 183-207.

Loo, J. van, A. de Grip en M. de Steur (2001), Skill Obsolescence: Causes and Cures, International Journal of Manpower, 21, pp. 121-137.

Maurin, E. and J. Moschion (2006), The Social Multiplier and Labour Market Participation of Mothers, IZA Discussion Paper No. 2513, Bonn.

Mourik, A. van, J.J. Siegers (1991), Labour Market Conditions and Labour Force Participation: The Case of the Netherlands, Applied Economics, Vol. 23, pp. 87-94.

Neumark, D. and Postlewaite, A. (1998), Relative Income Concerns and the Rise in Married Women's Employment, Journal of Public Economics, Vol. 70, pp. 157-183.

OCW (2001), Onderwijs, Cultuur en Wetenschappen in Kerncijfers 2002, Ministerie van Onderwijs, Cultuur en Wetenschappen, The Hague.

Oorschot, W. and C. Boos (2001), The Battle against Numbers: Dutch Disability Policies 1980-2000, European Journal of Social Security, Vol. 2, pp. 343-362.

Patterson, K. (2000), An Introduction to Applied Econometrics: A Time Series Approach, Palgrave, London.

Prieto-Rodriguez, J. and C. Rodriguez-Gutierrez (2000), The Added Worker Effect in the Spanish Case, Applied Economics, Vol. 32, pp. 1917-1925.

Romme, A.G.L. (1990), Projecting female labor supply: The Relevance of Social Norm Change, Journal of Economic Psychology, Vol. 11, pp. 85-99.

Schweitzer, S.O. and R.E. Smith (1974), The Persistence of the Discouraged Worker Effect, Industrial and Labor Relations Review, Vol. 27, pp. 249-260.

SCP (1999), Sociaal Cultureel Rapport 1998, The Hague.

SCP (2002), Emancipatiemonitor 2002, The Hague.

Seo, B. (1998), Tests for Structural Change in Cointegrated Systems, Econometric Theory, Vol. 14, 222-259.

Stephens, M. (2002), Worker Displacement and the Added Worker Effect, Journal of Labor Economics, Vol. 20, pp. 504-537.

Vendrik, M. (1993), Collective Habits and Social Norms in Labour Supply, From Micromotives to Macrobehaviour, Dissertation No. 93-18, Maastricht University.

Vendrik, M. (1998), Unstable Bandwagon and Habit Effects on Labor Supply, Journal of Economic Behavior and Organization, Vol. 36, pp. 235-255.

Vendrik, M.C.M. (2003a), Dynamics of a Household Norm in Female Labour Supply, Journal of Economic Dynamics \& Control, Vol. 27, pp. 823-841.

Vendrik, M.C.M. (2003b), Bandwagon Effects on female Labour Force Participation: An application to the Netherlands, in: Robin Cowan and Nicholas Jonard (eds.), Heterogeneous Agents, Interactions and Economic Performance, Lecture Notes in Economics and Mathematical Systems, Vol. 521, pp. 205-223. 
Vlasblom, J.D. (1997), Differences in Labour Supply and Income of Women in the Netherlands and the Federal Republic of Germany, Universitaire Pers Utrecht.

Woittiez, I. and A. Kapteyn (1998), Social Interactions and Habit Formation in a Model of Female Labour Supply, Journal of Public Economics, Vol. 70, pp. 185-205.

WRR (2000), Doorgroei en arbeidsparticipatie, Den Haag.

\section{Appendix A Cointegration and weak exogeneity tests}

The Johansen trace tests for cointegration of $\ln P_{m t}$ and $\ln D_{t}$ with a linear deterministic trend yield p-values for the null hypotheses of no and at most one cointegration relation that are indicated in Table A1. These $\mathrm{p}$-values clearly indicate that the $\mathrm{H}_{0}$ of no cointegration relation can be rejected at the $10 \%$ level, but the $\mathrm{H}_{0}$ of at most one cointegration relation cannot.

Insert Table A1

Lagrange-multiplier tests for weak exogeneity of $\ln D_{t}$ to $\ln P_{m t}$ and $\ln P_{f t}$ for the short-run parameters (WESP) were carried out as follows (Boswijk and Urbain, 1997). First, we estimated an unrestricted marginal equation for $\Delta \ln D_{t}$ in terms of two (respectively four) lagged differences of $\ln P_{m t}$ (respectively $\ln P_{f t}$ ) and $\ln D_{t}$ and a constant. Next, we added the residual of this equation to the optimal ECM for $\ln P_{m t}\left(\ln P_{f t}\right)$ as given by the left columns of Table 1. This yielded insignificant coefficients of the residual ( $\mathrm{p}=0.38$ for $\ln P_{m t}$ and $\mathrm{p}=0.24$ for $\ln P_{f t}$ ), implying WESP of $\ln D_{t}$ to $\ln P_{m t}$ and $\ln P_{f t}$.

Evidence for WESP of $\ln D_{t}$ and $\ln P_{f t}$ to $\ln P_{m t}$ in the extended ECM for $\ln P_{m t}$ was found in a similar way. An unrestricted marginal system for $\ln D_{t}$ and $\ln P_{f t}$ in terms of four lagged differences of $\ln P_{m t}, \ln D_{t}$ and $\ln P_{f t}$, a constant, and an error term for $\ln P_{f t}$ as in equation (2) was estimated, and the residuals were added to the optimal ECM for $\ln P_{m t}$ as given by the middle columns of Table 1 . This yielded insignificant coefficients of the residuals $(\mathrm{p}=0.54$ for F-statistic of Wald Test and $\mathrm{p}=0.90$ and 0.38 for residuals of $\ln D_{t}$ and $\ln P_{f t}$, separately). Adding a contemporaneous and lagged difference of the breakpoint dummy to the unrestricted system for $\ln D_{t}$ and $\ln P_{f t}$ and adding the residuals to the optimal ECM for $\ln P_{m t}$, as given by the right columns of Table 1, resulted in similarly insignificant coefficients of the residuals ( $\mathrm{p}=0.26$ for $\mathrm{F}$-statistic and $\mathrm{p}=0.22$ and 0.98 for separate residuals). Evidence for WESP of $\ln D_{t}$ and $\ln P_{m t}$ to $\ln P_{f t}$ in the extended ECM for $\ln P_{f t}$ was found by adding the residuals from an unrestricted marginal system for $\ln D_{t}$ and $\ln P_{m t}$ with one lag, a constant, an error term for $\ln P_{m t}$ and breakpoint dummy shock terms to the optimal ECM for $\ln P_{f t}$, yielding strongly insignificant coefficients of the residuals $(p=0.71$ for F-statistic and $p=0.92$ and 0.74 for separate residuals). 


\section{Appendix B Breakpoint tests and selection}

Critical values for the Quandt-Andrews test for the presence of an uncertain breakpoint have been derived by Andrews (1993) and Hansen (1992) for the case of regression equations without lags, but Seo (1998) has shown that applying the Quandt-Andrews test to stability of the cointegration and adjustment parameters in an error-correction model involves critical values that are similar to those of Hansen and Andrews. For a breakpoint in the coefficients of $\ln D_{t-1}$ and $\ln P_{f t-1}$ the maximum F-statistic is 13.02 (see Table 3), which is higher than the 5\% critical value value 12.52 in Table 3 of Seo (1998) for $\mathrm{p}=3, \mathrm{r}=1$ and $\mathrm{LM}_{2}$. Unfortunately, Seo (1998) does not derive critical values of the QuantAndrews (Q-A) statistic for a breakpoint in the constant $C$ in the cointegration relation, which is included in $\alpha_{m}$ in equation (1) (see footnote 12). It seems, however, plausible that critical values for a breakpoint in $C$ in combination with one or both of the two cointegration variables $\ln D_{t-1}$ and $\ln P_{f t-1}$ are similar to those for these cointegration variables. In general, we assume that the critical values of the Q-A test apply to breakpoints in the long-run parameters of $\ln D_{t-1}, \ln P_{f t-1}$ and $C$ separately as well in combination. Table B1 shows that especially for these variables separately the Q-A statistics are very high (around 26) with very low p-values. This also applies to the adjustment parameter of $\ln P_{m t-1}$, for which the critical values are those of the Q-A test (Seo, p. 233). This strongly suggests that there is a breakpoint in at least one of all these variables at $1995 .{ }^{25}$ To determine in which variable(s), we added breakpoint dummies for each of the four variables plus corresponding contemporaneous shock terms to the extended ECM in Table 1. Furthermore, we allowed for a possible time trend with break by adding time trend and pertinent breakpoint dummies. Additional lags were insignificant, but, due to the addition of so many breakpoint dummies, there was considerable serial correlation in the residual $(\mathrm{p}=0.001)$, which could not be removed by adding lags. Therefore, insignificant variables were eliminated on the basis of Newey-West-corrected standard errors. This led to the estimates as presented in the last columns of Table 1.

Insert Table B1

\section{Appendix C Relative size of added-worker effect}

Assume that in the long run the total contribution $L$ of the numbers of male workers $L_{m}$ and female workers $L_{f}$ to the macro production function is given by $L=c L_{m}{ }^{\beta} L_{f}{ }^{1-\beta}$ with $0<\beta<1$ and $c>$ 0 . This implies $L_{f}=\left(\frac{1}{c} L L_{m}^{-\beta}\right)^{1 /(1-\beta)}$. Hence, the demand for female labour is given by $L_{f}{ }^{D}=\left(\frac{1}{c} L^{D} L_{m}{ }^{S^{-\beta}}\right)^{1 /(1-\beta)}$, where the superscript $D$ refers to demand and $S$ to supply. Dividing these demands and supplies by the corresponding working age population sizes, assuming that the male and

\footnotetext{
${ }^{25}$ We also checked for a second breakpoint by carrying out Q-A tests for a breakpoint in the subsample from 1969 to 1994, but this yielded very insignificant Q-A statistics.
} 
female working age populations are approximately equal in number and approximating $L^{D}$ by total employment plus vacancies in persons, it easily follows that the female labour demand rate is given by $D_{f}=\left(\frac{2}{c} D P_{m}^{-\beta}\right)^{1 /(1-\beta)}$, or in logs: $\ln D_{f}=\frac{1}{1-\beta}\left(\ln D-\beta \ln P_{m}\right)$, where we dropped the additive constant term.

The long-run relation of $\ln P_{f t}$ to $\ln D_{t}$ and $\ln P_{m t}$ according to Table 2 can be written in a comparable form as $\ln P_{f t}^{*}=0.655 \ln D_{t}-1.772 \ln P_{m t}=0.655\left(\ln D_{t}-\frac{1.772}{0.655} \ln P_{m t}\right)$. We then see that the ratio $1.772 / 0.655=2.705$ corresponds to $\beta$ in the equation for $\ln D_{f}$ above. However, the former ratio is much higher than the upperbound 1 of $\beta$, indicating that there is an added-worker effect (AWE) in excess of the substitution effect at the demand side of the labour market as expressed by $\beta$. The share of this AWE in the total substitution effect is at least equal to $(2.705-1) / 2.705 \times 100=63 \%$. We can also derive an upper bound for the share of AWE from a derivation of the male labour demand rate $D_{m}$ analogous to that for the female labour demand rate above. This yields $\ln D_{m}=\frac{1}{\beta}\left[\ln D-(1-\beta) \ln P_{f}\right]$, which corresponds to the long-run relation of $\ln P_{m t}$ to $\ln D_{t}$ and $\ln P_{f t}$ according to Table 1: $\ln P_{m t}^{*}=0.370 \ln D_{t}-0.285 \ln P_{f t}=0.370\left(\ln D_{t}-\frac{0.285}{0.370} \ln P_{f t}\right)$. The ratio $0.285 / 0.370=0.770$ corresponds to $1-\beta$ in the equation for $\ln D_{m}$ above. Equating $1-\beta$ to 0.770 yields $\beta=0.330$. However, since men work more hours than women, it is plausible that $\beta$ will be greater than 0.5 , and hence $1-\beta$ smaller than 0.5 . This would imply that ratio 0.770 also contains an ADE from female to male participation which is at least $(0.77-0.5) / 0.77 \times 100=35 \%$ of the total substitution effect from female to male participation. Furthermore, taking 0.5 as a lower bound for $\beta$ implies an upper bound for the share of the AWE from male to female participation of $(2.705-0.5) / 2.705 \times 100=82 \%$.

\section{Appendix D Underlying structural model}

An interesting structural model which is consistent with the estimated extended ECM equation (1) with breakpoint for male participation (see the right columns of Table 1) is given by the following equation:

$$
\begin{aligned}
\ln P_{m t}= & \alpha_{m}^{S}+\beta_{m 0}^{S} \ln D_{t}+\beta_{m 1}^{S} \sum_{i=0}^{\infty} \lambda^{i} \ln D_{t-1-i}+\varphi_{m 0}^{S} \ln P_{f t}+\gamma_{m 1}^{S} \ln P_{m t-1}+\gamma_{m 2}^{S} \sum_{j=0}^{\infty} \lambda^{j} \ln P_{m t-2-j}+ \\
& +\chi_{m 0}^{S} D U M_{94 t}+\chi_{m 1}^{S} \sum_{k=0}^{\infty} \lambda^{k} D U M_{94 t-1-k}+\varepsilon_{m t}^{s} .
\end{aligned}
$$

Here the Greek symbols indicate the parameters and residual with superscript $S$ for "structural". The parameter $\lambda$ indicates the factor by which the weights of further lags of the pertinent variables decline and has a value between 0 and 1 . The sums of these weighted lags can be conveniently expressed in terms of the lag operator $L$ as $\sum_{i=0}^{\infty}(\lambda L)^{i} \ln D_{t-1}=\ln D_{t-1} /(1-\lambda L)$ etc., allowing a Koyck transformation $1-\lambda L$ of the left and right-hand sides of equation (D1). This yields an ADL equation in terms of only current and one-year-lagged values of variables, which can easily be rewritten in the 
ECM form of the estimated extended equation (1). This yields the following relations between the ECM parameters in Table 1 and the structural parameters in equation (1):

$$
\begin{aligned}
& \alpha_{m}=(1-\lambda) \alpha_{m}^{S}, \quad \beta_{m 0}=\beta_{m 0}^{S}, \quad \varphi_{m 0}=\varphi_{m 0}^{S}, \gamma_{m 1}=\lambda \gamma_{m 1}^{S}-\gamma_{m 2}^{S}, \chi_{m 0}=\chi_{m 0}^{S}, \\
& \rho_{m}=(1-\lambda)\left[1-\gamma_{m 1}^{S}-\gamma_{m 2}^{S} /(1-\lambda)\right], \\
& \delta_{m}=\frac{\beta_{m 0}^{S}+\beta_{m 1}^{S} /(1-\lambda)}{1-\gamma_{m 1}^{S}-\gamma_{m 2}^{S} /(1-\lambda)}, \quad \varsigma_{m}=\frac{\varphi_{m 0}^{S}}{1-\gamma_{m 1}^{S}-\gamma_{m 2}^{S} /(1-\lambda)}, \quad \psi_{m}=\frac{\chi_{m 0}^{S}+\chi_{m 1}^{S} /(1-\lambda)}{1-\gamma_{m 1}^{S}-\gamma_{m 2}^{S} /(1-\lambda)} .
\end{aligned}
$$

Inversely, the structural parameters can be expressed in the estimated ECM-parameters, which yields the following values for the structural parameters: $\alpha_{m 0}^{S}=1.865, \beta_{m 0}^{S}=0.166, \beta_{m 1}^{S}=0.097$, $\lambda=0.549, \quad \varphi_{m 0}^{S}=-0.293, \quad \gamma_{m 1}^{S}=-0.237, \quad \gamma_{m 2}^{S}=0.092, \quad \chi_{m 0}^{S}=0.0094, \chi_{m 1}^{S}=0.0227$. Thus, the structural model for male participation exhibits positive current and lagged labour demand effects, a negative substitution effect from female participation, a negative feedback effect from one-year-lagged male participation, a smaller positive feedback effect from two-and-more-years-lagged male participation, and positive current and lagged exogenous policy effects. Thus, in the one-year feedback effect the negative effects of lagged on current male participation via discouraged worker and timing effects dominate the positive bandwagon and work experience effects (see Section 2), whereas in a longer run the latter effects are stronger than the former effects. In the ECM as opposed to the structural model, there is also a positive feedback effect from lagged on current male participation as a result of the Koyck transformation $1-\lambda L$. This leads to persistence in the male participation rate as expressed by equation (D4b) for the adjustment parameter $\rho_{m}=0.466$ (Table 1 ). In this equation the factor $1-\lambda$ equals 0.451 , whereas the factor $1-\gamma_{m 1}^{S}-\gamma_{m 2}^{S} /(1-\lambda)$ is equal to 1.033 . Thus, in the longrun the persistence-reducing effect of the negative feedbacks via discouraged-worker and timing effects just dominates the persistence-increasing effect of the positive bandwagon and work experience feedbacks, leaving the distributed lags in the working of the explanatory variables as the decisive source of persistence in the male participation rate. In addition, the ECM includes a negative feedback shock effect from changes in the lagged male participation rate $\left(\gamma_{m 1}=-0.222\right.$ in Table 1$)$, which according to the relation $\gamma_{m 1}=\lambda \gamma_{m 1}^{s}-\gamma_{m 2}^{s}$ under (D4a) stems from an interaction of the distributed lags and the negative feedback from one-year-lagged participation minus the positive feedback from two-or-more-years-lagged participation. ${ }^{26}$ This negative feedback has the effect of further delaying the adjustment to the long-run equilibrium path.

\footnotetext{
${ }^{26}$ The predominance of negative discouraged-worker feedbacks over positive bandwagon and work-experience feedbacks is even stronger in the other two structural models with exponentially distributed lags that are consistent with the estimated extended ECM for male participation. In the first model the distributed lag of $\ln P_{m t}$ $2-j$ is replaced by an analogous distributed lag of $\ln P_{f t-1-j}$, leading to a somewhat higher $\lambda=0.652$ and $\gamma_{m 1}^{S}=-0.340$. The second model contains more complex distributed lags with two parameters $\lambda$ and $\mu$ that are equal to the two values of $\lambda$ in the two simpler models, and implies $\gamma_{m 1}^{S}=-0.891$ with a distributed lag and no $\gamma_{m 2}^{S}$.
} 
For the extended ECM for female participation a similar underlying distributed-lags model can be found. For reasons of space we do not elaborate this here, but we only mention some main results. Since the cointegration restrictions on $\ln D_{t-1}$ and $D U M_{94 t-1}$ in the ECM correspond to complex restrictions in an underlying distributed-lags model, we simplified by deriving an underlying model for the corresponding unrestricted ECM, which has estimated coefficients that do not differ significantly from those of the restricted ECM (see footnote 19). A suitable distributed-lags model implies $\lambda=$ 0.489 , predominantly positive labour demand coefficients, predominantly negative substitution coefficients from male participation, positive exogenous-policy coefficients, and feedback coefficients that alternate from positive for $\ln P_{f t-1}$ to considerably negative for $\ln P_{f t-4}$. The feedback coefficients lead to a factor $1-\gamma_{m 1}^{S}-\gamma_{m 2}^{S}-\gamma_{m 3}^{S}-\gamma_{m 4}^{S} /(1-\lambda)=1.17$ in the expression for the adjustment parameter $\rho_{f}=0.599$ (analogous to relation (D4b)), while the factor $1-\lambda=0.511$ in this expression makes the adjustment parameter considerably lower than one. Thus, just as for male participation, the distributed lags in the working of the explanatory variables are the decisive source of persistence in the female participation rate. 


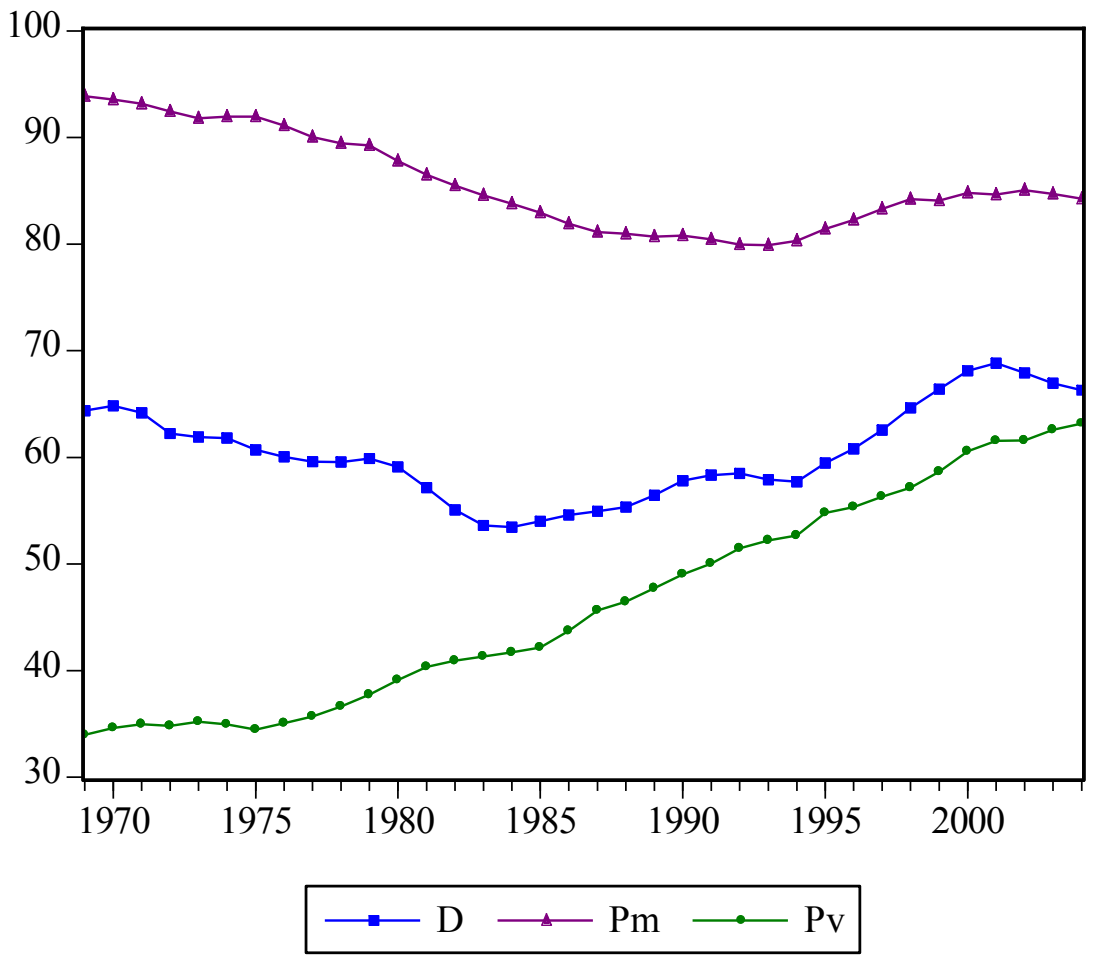

Figure 1: Male and female participation rates $\left(P_{m}\right.$ and $\left.P_{f}\right)$ and labour demand rate $(D)$ in the Netherlands, as percentages of the potential labour force, 1969-2004

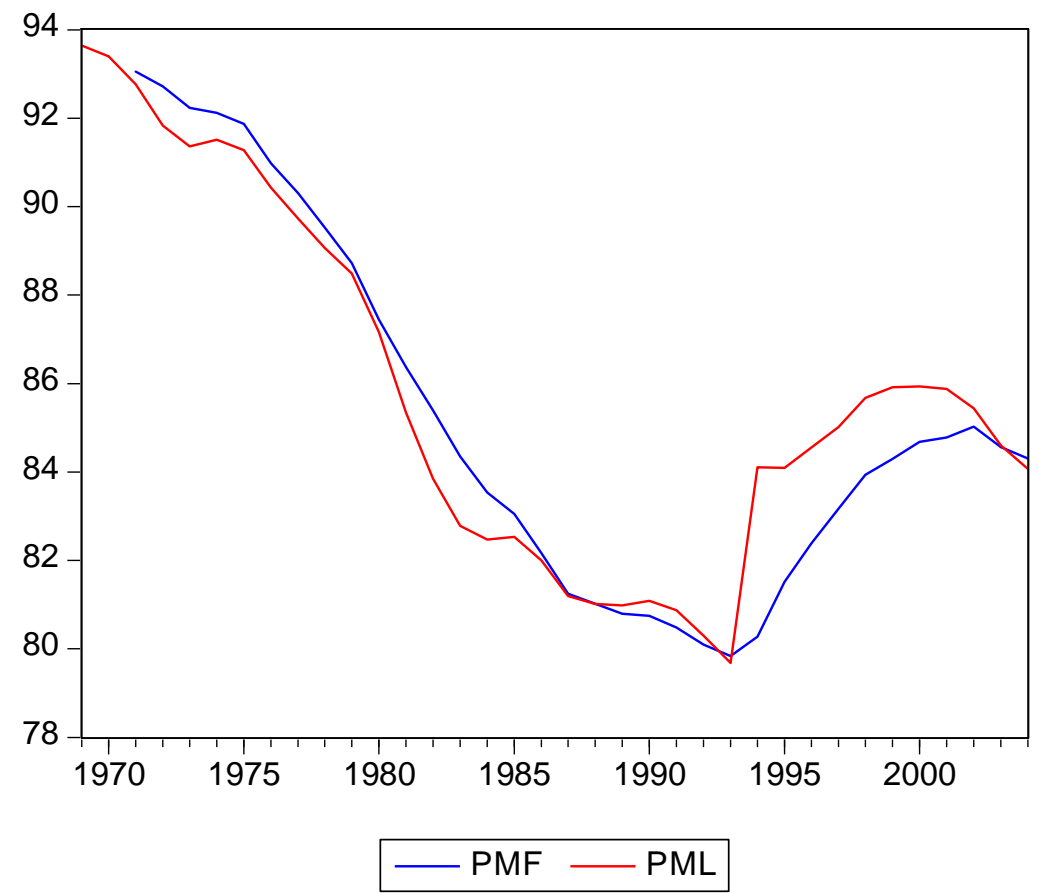

Figure 2: Fitted (PMF) and long-run (PML) male participation rates, 1969-2004 


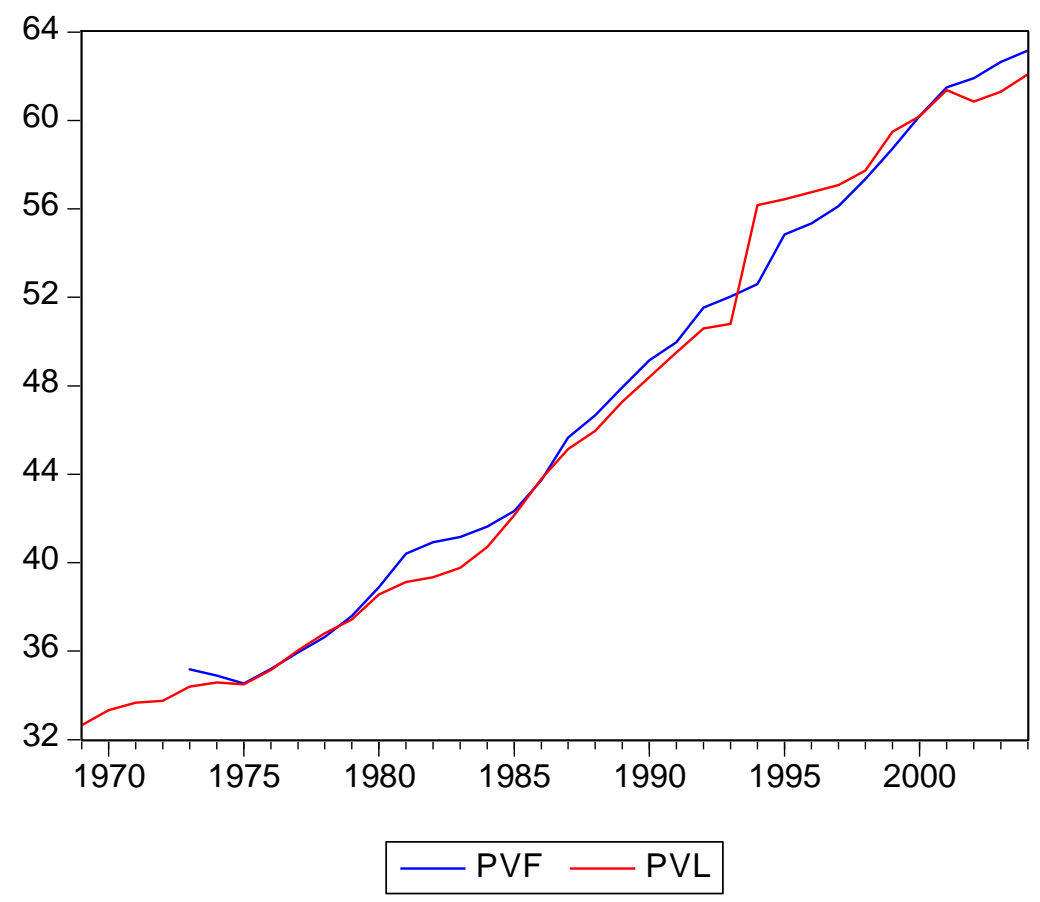

Figure 3: Fitted (PVF) and long-run (PVL) female participation rates, 1969-2004 
Equation $1 \quad$ Extended equation $1 \quad$ Extended equation 1

\begin{tabular}{|c|c|c|c|c|c|c|c|}
\hline Variable & Coefficient & Estimate & T-ratio & Estimate & T-ratio & Estimate & T-ratio \\
\hline Constant & $\alpha_{m}$ & 0.498 . & 2.78 & 0.649 & 2.46 & 1.865 & 10.05 \\
\hline$\Delta \ln D_{t}$ & $\beta_{m 0}$ & 0.190 & 3.14 & 0.365 & 4.19 & 0.166 & 3.96 \\
\hline$\Delta \ln D_{t-1}$ & $\beta_{m 1}$ & & & -0.216 & -1.88 & & \\
\hline$\Delta \ln D_{t-2}$ & $\beta_{m 2}$ & -0.164 & -2.43 & & & & \\
\hline$\Delta \ln P_{m t-1}$ & $\gamma_{m 1}$ & 0.315 & 1.77 & 0.292 & 1.51 & -0.222 & -2.00 \\
\hline$\Delta \ln P_{f t}$ & $\varphi_{m 0}$ & & & -0.237 & -3.77 & -0.293 & -9.34 \\
\hline$\Delta \ln P_{f t-1}$ & $\varphi_{m 1}$ & & & 0.112 & 1.52 & & \\
\hline$\Delta D U M_{94 t}$ & $\chi_{m 0}$ & & & & & 0.00937 & 10.54 \\
\hline $\ln P_{m t-1}$ & $\rho_{m}$ & 0.235 & 3.51 & 0.225 & 3.00 & 0.466 & 9.87 \\
\hline $\ln D_{t-1}$ & $\delta_{m}$ & 0.584 & 7.95 & 0.572 & 7.25 & 0.370 & 19.96 \\
\hline $\ln P_{f t-1}$ & $\varsigma_{m}$ & & & -0.204 & -8.41 & -0.285 & -56.79 \\
\hline$T$ & $\theta_{m}$ & -0.00393 & -8.90 & & & & \\
\hline$D U M_{94 t-1}$ & $\psi_{m}$ & & & & & 0.0578 & 15.68 \\
\hline $\begin{array}{c}\text { No. of } \\
\text { observations }\end{array}$ & & 33 & & 34 & & 34 & \\
\hline Adjusted $\mathrm{R}^{2}$ & & 0.644 & & 0.709 & & 0.877 & \\
\hline Log likelihood & & 133.19 & & 142.31 & & 157.03 & \\
\hline $\begin{array}{l}\text { Schwartz } \\
\text { criterion }\end{array}$ & & -7.330 & & -7.438 & & -8.304 & \\
\hline D-W statistic & & 2.16 & & 2.14 & & 2.26 & \\
\hline $\mathrm{p}[\mathrm{elim}$. par. $=0]$ & & 0.56 & & 1.00 & & 0.48 & \\
\hline $\mathrm{p}$ [AR 1-4] & & 0.66 & & 0.75 & & 0.34 & \\
\hline $\mathrm{P}\left[\mathrm{X}_{\mathrm{i}}\right], \mathrm{p}\left[\mathrm{X}_{\mathrm{i}}^{2}\right]$ & & $0.02,0.21$ & & $0.11,0.10$ & & $0.46,0.96$ & \\
\hline $\mathrm{P}$ [Normality] & & 0.56 & & 0.58 & & 0.83 & \\
\hline
\end{tabular}

Table 1: Estimation results for male participation in basic and extended ECM. The p[.] denote p-values of diagnostic test statistics against joint significance of eliminated parameters (Wald test), first-to-fourth order serial correlation, heteroscedasticity (Breusch-Pagan-Godfrey, White quadratic), and non- normality. The tvalues of the coefficients are White heteroscedasticity consistent for the equations without breakpoint and Newey-West heteroscedasticity-and-autocorrelation consistent for the equation with breakpoint. All coefficients are significant at $\boldsymbol{p}=0.10$ except those of $\Delta \ln P_{m t-1}(p=0.14)$ and $\Delta \ln P_{f t-1}(p=0.14)$ in the extended equation without breakpoint. 
Equation 2

Extended equation 2

\begin{tabular}{|c|c|c|c|c|c|}
\hline Variable & Coefficient & Estimate & T-ratio & Estimate & T-ratio \\
\hline Constant & $\alpha_{f}$ & 1.735 & 5.17 & 4.949 & 11.05 \\
\hline$\Delta \ln D_{t}$ & $\beta_{f 0}$ & 0.500 & 2.31 & 0.456 & 4.80 \\
\hline$\Delta \ln D_{t-1}$ & $\beta_{f 1}$ & -0.471 & -1.74 & -0.246 & -1.90 \\
\hline$\Delta \ln D_{t-2}$ & $\beta_{f 2}$ & 0.563 & 5.19 & 0.302 & 4.58 \\
\hline$\Delta \ln P_{f t-1}$ & $\gamma_{f 1}$ & 0.483 & 4.50 & 0.167 & 1.84 \\
\hline$\Delta \ln P_{f t-3}$ & $\gamma_{f 3}$ & 0.207 & 1.84 & 0.326 & 4.98 \\
\hline$\Delta \ln P_{f t-4}$ & $\gamma_{f 4}$ & 0.169 & 1.65 & & \\
\hline$\Delta \ln P_{m t}$ & & & & -1.549 & -9.01 \\
\hline$\Delta \ln P_{m t-1}$ & & & & -0.542 & -2.31 \\
\hline$\Delta D U M_{94 t}$ & & & & 0.0156 & 6.27 \\
\hline $\ln P_{f t-1}$ & $\rho_{f}$ & 0.504 & 5.13 & 0.562 & 10.97 \\
\hline $\ln D_{t-1}$ & $\delta_{f}$ & & & 0.655 & \\
\hline $\ln P_{m t-1}$ & & & & -1.772 & \\
\hline$T$ & $\phi_{f}$ & 0.0197 & 62.83 & 0.0094 & 8.22 \\
\hline$D U M_{94 t-1}$ & & & & 0.102 & \\
\hline $\begin{array}{l}\text { Number of } \\
\text { observations }\end{array}$ & & 31 & & 32 & 32 \\
\hline Adjusted $\mathrm{R}^{2}$ & & 0.665 & & 0.899 & \\
\hline Log likelihood & & 112.92 & & 138.17 & \\
\hline $\begin{array}{l}\text { Schwartz } \\
\text { criterion (SIC) }\end{array}$ & & -6.288 & & -7.336 & \\
\hline $\begin{array}{l}\text { Durbin-Watson } \\
\text { statistic }\end{array}$ & & 2.03 & & 2.03 & \\
\hline $\mathrm{p}[$ elim. par. $=0]$ & & 0.80 & & 0.25 & \\
\hline $\mathrm{p}[\mathrm{AR} 1-4]$ & & 0.54 & & 0.01 & \\
\hline $\mathrm{p}\left[\mathrm{X}_{\mathrm{i}}\right], \mathrm{p}\left[\mathrm{X}_{\mathrm{i}}^{2}\right]$ & & $0.37,0.48$ & & $0.68,0.20$ & \\
\hline $\mathrm{P}$ [Normality] & & 0.39 & & 0.78 & \\
\hline
\end{tabular}

Table 2: Estimation results for female participation in basic and extended ECM. The p[.] denote p-values of diagnostic test statistics against joint significance of eliminated parameters (Wald test), first-to-fourth order serial correlation, heteroscedasticity (Breusch-Pagan-Godfrey, White quadratic), and non-normality. The tvalues of the coefficients are Newey-West heteroscedasticity-and-autocorrelation consistent. All coefficients are significant at $p=0.10$ except that of $\Delta \ln P_{f t-4}(p=0.11)$ in the extended equation without breakpoint. 


\begin{tabular}{|c|c|c|c|c|}
\hline Effect & $\begin{array}{l}\text { Men } \\
\text { \%-points }\end{array}$ & & $\begin{array}{l}\text { Women } \\
\% \text {-points }\end{array}$ & \\
\hline Model simulation & 4.6 & & 8.8 & \\
\hline Labour demand & & 4.5 & & 8.0 \\
\hline Adjustment to long-run equilibrium in 1994 & & 3.6 & & 3.9 \\
\hline Feedback shocks from before 1994 & & 0.0 & & -0.1 \\
\hline Substitution by females/males & & -3.6 & & -7.1 \\
\hline Autonomous trend & & - & & 4.0 \\
\hline Population composition & -0.3 & & 0.7 & \\
\hline Age class & & -0.2 & & -1.5 \\
\hline Educational level & & 0.5 & & 2.4 \\
\hline Ethnical background & & -0.5 & & -0.5 \\
\hline Household composition & & -0.1 & & 0.3 \\
\hline Total increase from model and population & 4.3 & & 9.5 & \\
\hline Residual & 0.0 & & -0.7 & \\
\hline
\end{tabular}

Table 3: Decomposition of the increase in labour force participation in the 1994-2001 upturn of the Dutch economy

\begin{tabular}{|c|c|c|c|c|}
\hline Effect & $\begin{array}{l}\text { Men } \\
\text { \%-points }\end{array}$ & & $\begin{array}{l}\text { Women } \\
\% \text {-points }\end{array}$ & \\
\hline Model simulation & -0.3 & & 1.4 & \\
\hline Labour demand & & -0.7 & & -1.1 \\
\hline Adjustment to long-run equilibrium in 2001 & & 1.0 & & -0.2 \\
\hline Feedback shocks from before 2001 & & 0.0 & & 0.9 \\
\hline Substitution by females/males & & -0.6 & & 0.4 \\
\hline Autonomous trend & & - & & 1.5 \\
\hline Population composition & -0.6 & & 0.2 & \\
\hline Age class & & -0.8 & & -0.9 \\
\hline Educational level & & 0.5 & & 1.3 \\
\hline Ethnical background & & -0.1 & & -0.1 \\
\hline Household composition & & -0.2 & & -0.1 \\
\hline Total increase from model and population & -0.9 & & 1.7 & \\
\hline Residual & 0.6 & & -0.0 & \\
\hline
\end{tabular}

Table 4: Decomposition of the increase in labour force participation in the 2001-2004 downturn of the Dutch economy 


\begin{tabular}{|l|l|l|l|}
\hline & \multicolumn{3}{|c|}{ No. of lags in shock terms } \\
\hline $\begin{array}{l}\text { No. of cointegration } \\
\text { relations under H0 }\end{array}$ & 0 & 1 & 2 \\
\hline 0 & 0.060 & 0.054 & 0.099 \\
\hline At most 1 & 0.375 & 0.492 & 0.141 \\
\hline
\end{tabular}

Table A1: P-values for Johansen trace tests for cointegration of $\ln P_{m t}$ and $\ln D_{t}$ with a linear deterministic trend for zero, one and two lags in the shock terms.

\begin{tabular}{|c|c|c|c|c|c|c|c|}
\hline $\begin{array}{c}\text { Variables with } \\
\text { breakpoint }\end{array}$ & $\ln D_{t-1} \ln P_{f t-1}$ & $\ln D_{t-1} C$ & $\ln P_{f t-1} C$ & $\ln D_{t-1}$ & $\ln P_{f t-1}$ & $C$ & $\ln P_{m t-1}$ \\
\hline $\begin{array}{c}\text { Maximum F-statistic } \\
(1995)\end{array}$ & 13.02 & 12.56 & 13.36 & 26.04 & 25.76 & 26.14 & 26.11 \\
\hline Probability & 0.027 & 0.033 & 0.023 & 0.000 & 0.000 & 0.000 & 0.000 \\
\hline
\end{tabular}

Table B1: Significant Quandt-Andrews statistics and p-values for long-run parameters and adjustment parameter of extended ECM for $\ln P_{m t}$. 